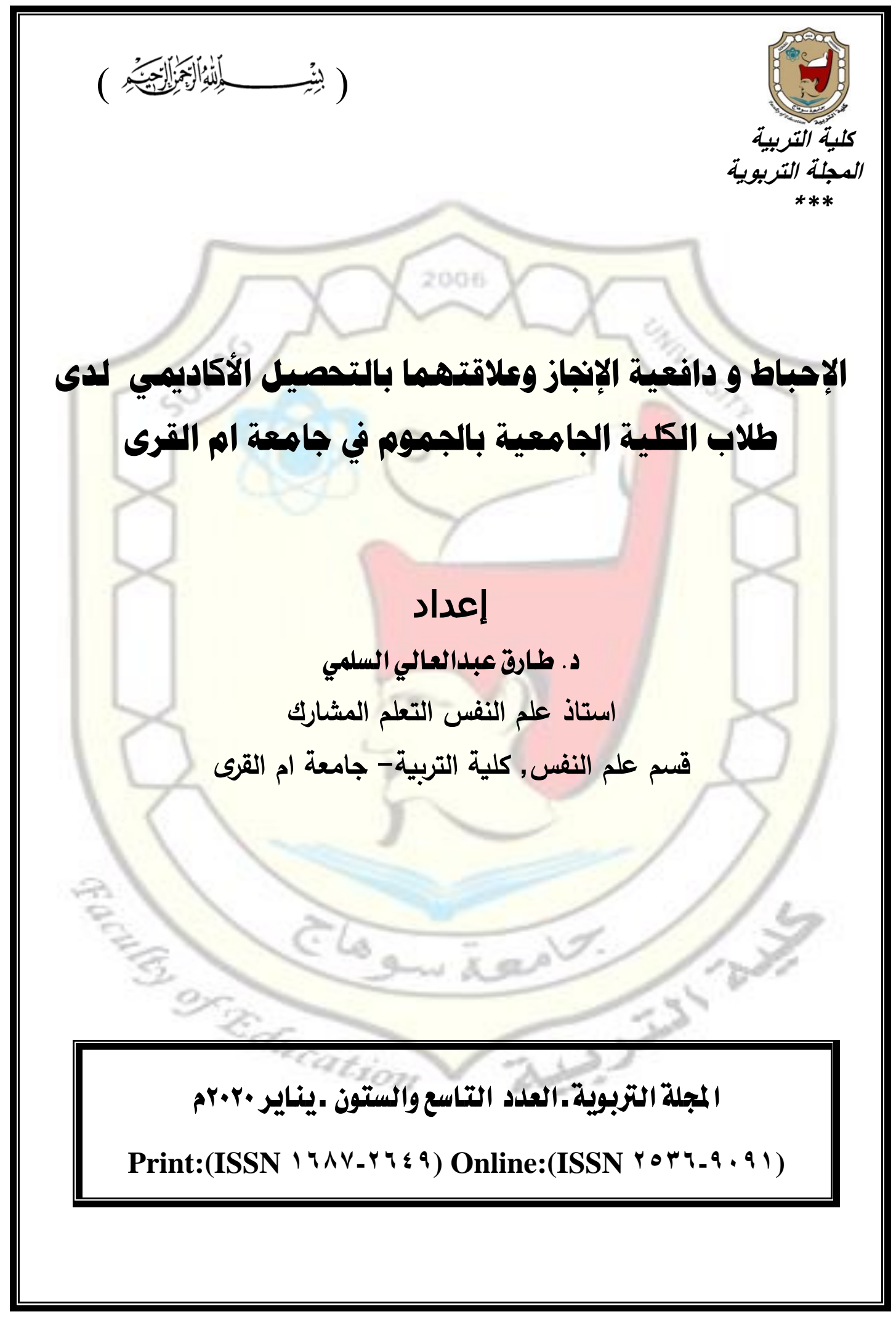




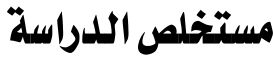

هدفت الدارسة الحالية الى التعرف على مستوى الإحباط و دافعية الانجاز وعلاقتهما

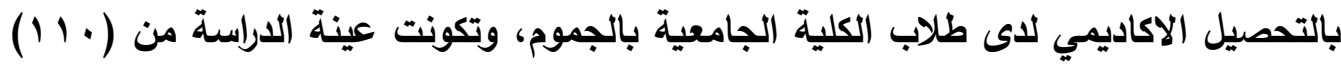

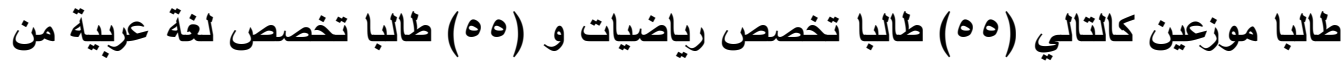
طلاب الكلية الجامعية في الجموم بجامعة ام القرى، ولتحقيق اهداف الدارسة تم بناء مقياسي

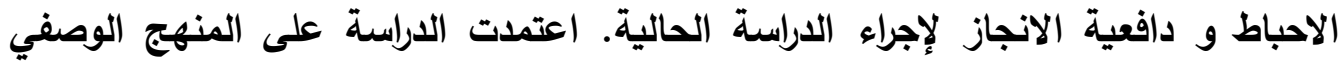

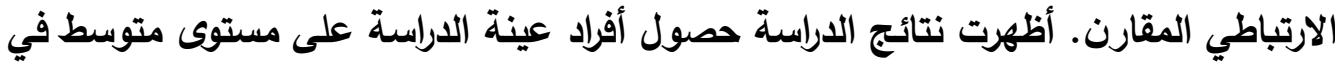

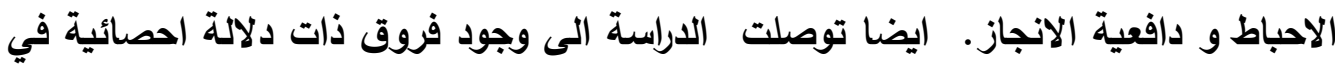

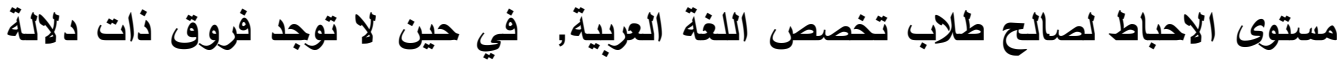
احصائية في مستوى دافعية الانجاز تعزى الى التخصص الاكاديمي. ايضا توصلت الدراسية الى وجود علاقة ارتباطية سالبة ذات دلالة احصائية بين مستوى الاحباط والتحصيل الاكاديمي للطلاب. ايضا توصلت الداسة الى وجود علاقة ارتباطية موجبة بين مستوى دافعية الانجاز والتحصيل الاكاديمي لاى الطلاب. من جهة اخرى توجد علاقة ارتباطية سالبة بين مستوى الاحباط ودافعية الانجاز. وفي نهاية الدراسة تم التوصية بإجراء البرامج الارشادية للد من الاحباط وتحسين دافع الانجاز لاى طلاب الكلية الجامعية بالجموم.

الكلمات المفتاحية: الاحباط، دافعية الانجاز، التحصيل الاكاديمي، طلاب الكلية الجامعية 
The Frustration and achievement motivation and their relation to academic achievement among the students of the university college in Aljamoum at Umm Al Qura University

\author{
Dr. Tareq A. ALSilami \\ Associate Professor of Learning Psychology \\ Department of Psychology, Faculty of Education \\ UMM AL-QURA University
}

\begin{abstract}
The present study aimed to identify the levels of frustration and achievement motivation and their relation to academic achievement among the students of the university college in Aljamoum at Umm Al Qura University. The sample of the study consisted of (11.) students, distributed as follows: $(\theta \Delta)$ students in mathematics specializing and $(\theta \theta)$ students in Arabic language specializing. To achieve the goals of current study the researcher constructed both scales of frustration and achievement motivation. The researcher used descriptive correlation approach. The study found that the frustration and the achievement motivation were average level. Also, the study found that there were statistically significant differences in the level of frustration in favor of students in Arabic language specialization, while there were no statistically significant differences in achievement motivation due to academic specialization. The study found a statistically significant negative relationship between the level of frustration and academic achievement of students, whereas the study found a positive correlation between the level of the motivation achievement and the academic achievement among students. On the other hand, there is a negative correlation between the level of frustration and the level of motivation achievement. At the end of the study, it is recommended to organize training courses and workshops to reduce the levels of frustration and improve the achievement motivation for students of the university college in Aljamoum.
\end{abstract}

Keywords: Frustration, Achievement Motivation, Academic Achievement, students university college. 


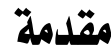

الاحباط Frustration عند الفرد بصفة عامة والطلاب بصفة خاصة عامل مؤثر على عدم استقرار الطالب نفسيا مما قد يعيق تقدمه في مراحله الدراسية ويجعله مكبل

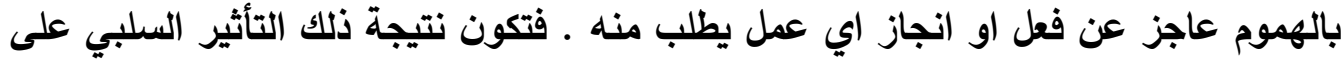

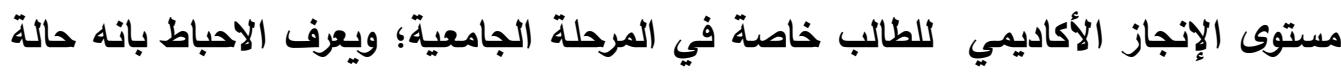

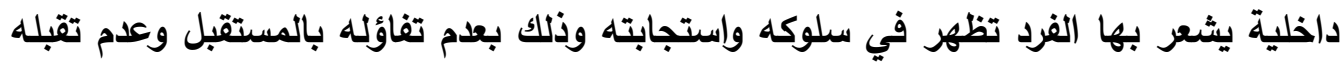

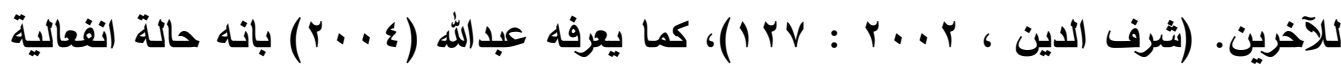

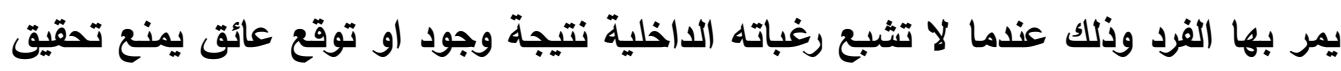

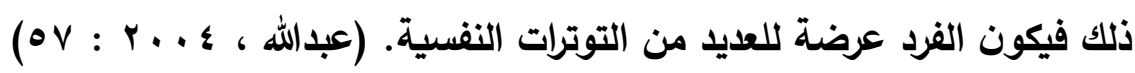

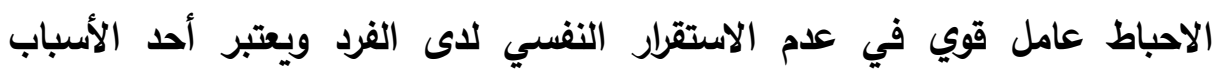

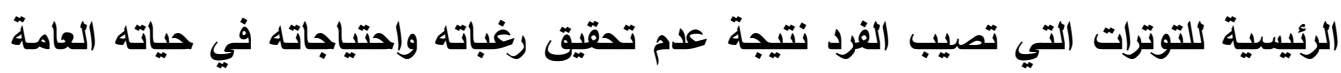
وذلك لوجود او توقع عوائق تمنع تحقيق اهدافه، زمن ثم فإن الإحباط يؤثر بثكل سلبي على فئل

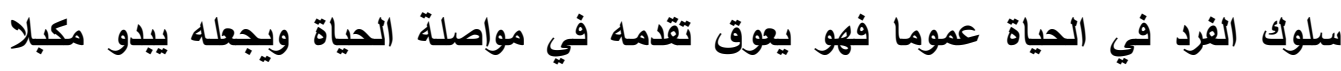

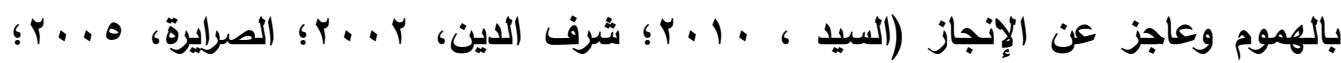
عبدالله، ع... (r). انواع الاحباط: 1- الاحباط الاولي والاحباط الثانوي: الاحباط الاولي عبارة عن حالة

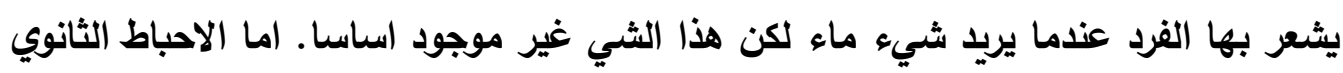

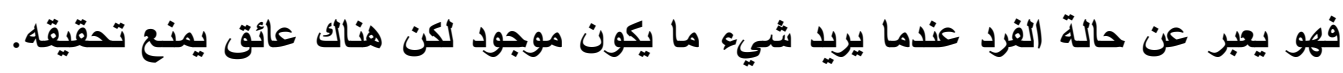

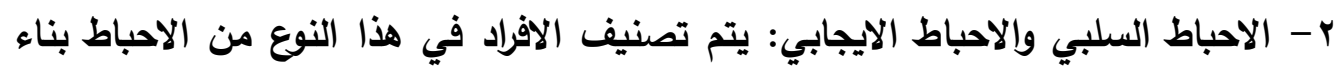

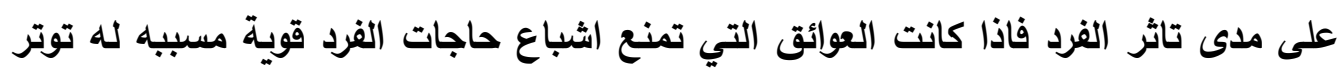

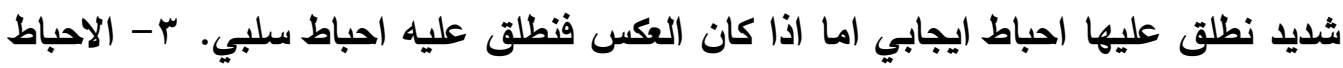

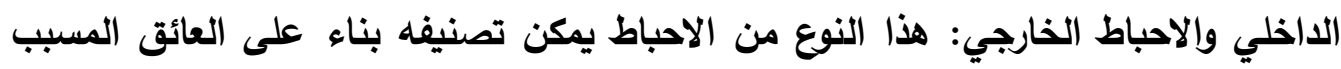

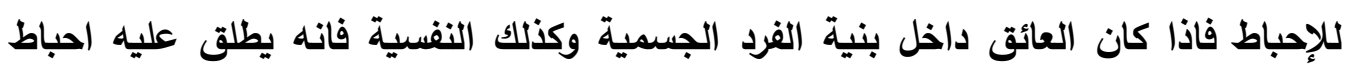

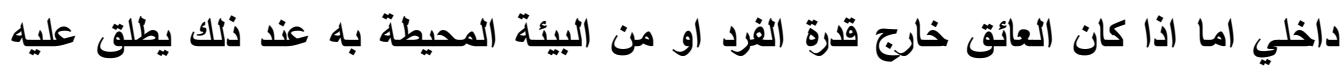

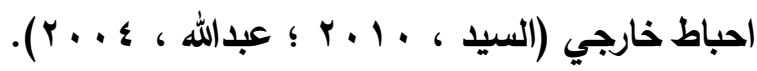


نواتج الاحباط: اشار ابو حطب وصادق (9Av) ان الاحباط عبارة عن اعاقة لنشاط يفترض الفرد ان يقوم به ليحقق اهدافه او هدف معين فينتج عن ذلك شعور الفرد بخيبة الامل والعجز مما قد يسبب له النكوص عند الفرد او استجابة عدوانية. كما اكد عبدالله

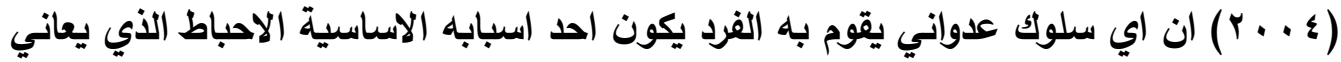
منه الفرد فينتج عن ذلك العدوان كتنفيس عن احباط الفرد فيكون العدوان الذي يمكن تصنيفه الى عدة اشكال: لفظيا ، جسميا ، مباشر او غير مباشر. مستويات الاحباط: اولا مستوى الاحباط المنخفض: والمقصود بهذا المستوى هو الاحباط البسيط (العادي) الذي لا يؤثر على الفرد كثيرا بل ان الفرد يستطيع ان يتغلب عليه وذلك بالاجتهاد والمثابرة لان العوائق في هذا المستوى تكون ضعيفة. ثانيا مستوى الاحباط المتوسط والمرتفع: في هذين المستويين تكون العوائق لتحقيق اهداف الفرد قوية لا يمكن تجاوزها فتسبب الاحباط لاى الفرد فيلجا الفرد الى الحيل الدفاعية للتنفيس من اثر الاحباط

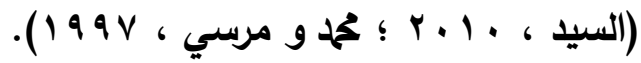
الاحباط والصحة النفسية: علاقة الاحباط بالصحة النفسية تعتمد على مستوى الاحباط عند الفرد فاذا كان مستوى الاحباط عند الفرد منخفض فانه عادة الفرد يتغلب على هذا المستوى البسيط من الاحباط وذلك بالاجتهاد والمثابرة حتى يصل الى طريق النجاح وتحقيق اهدافه. اما اذا كان مستوى الاحباط عند الفرد متوسط او مرتفع بالتالي تكون العوائق التي تمنع وصول الفرد الى تحقيق اهدافه قوية بالتالي لا يستطيع الفرد اجتيازها والتغلب عليها مما قد تسبب لاى الفرد الثعور بالإحباط والاكتئاب والتقلق والكثير من الامراض النفسية التي ينتج عنها النكوص والعدوان (حسين و حسين ، ج . . ب ؛ محمد و

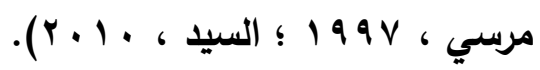

اما فيما يتعلق بدافعية الانجاز يعد مواري من الاوائل الذين اشاروا الى مفهوم الحاجة الى الانجاز بثكل واضح وربطه بمكونات شخصية الفرد الاساسية (اليوسف،

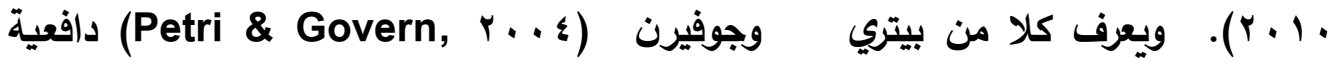
الانجاز بجزء من شخصية الفرد ذات الثبات النسبي يتم فيها تحديد مدى قدرة الفرد ومثابرته

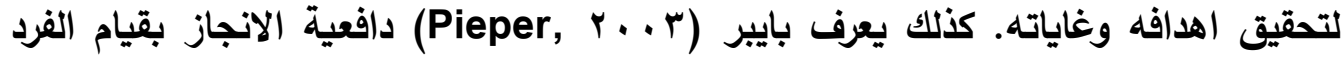
بإنجاز اهدافه وغاياته بكفاءة وشكل افضل مما كان عليه سابقا. كذلك عرفه مواري (9^^ ا ) 


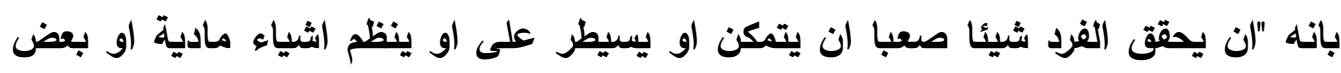
افراد الانسان او الافكار ان يقوم بهذا بأكبر سرعة ممكنة او تأكيد قدر ممكن من الاستقلال

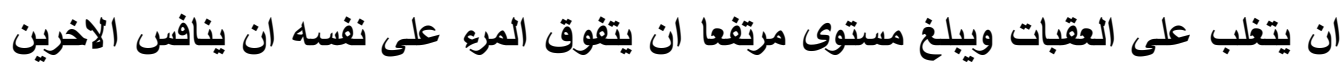

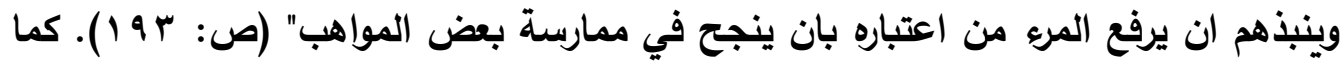

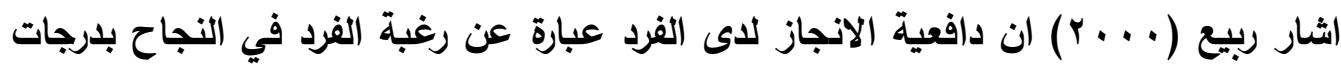

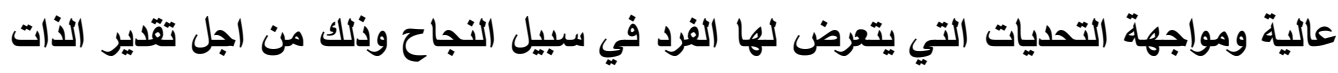

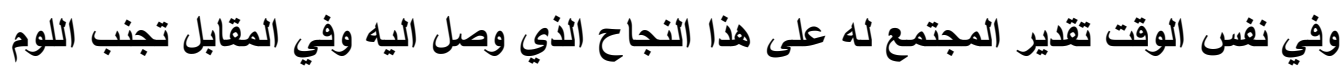

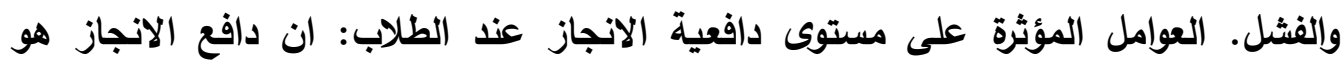
استعداد مكتسب بهذف الوصول الى النجاح وهو يختلف من اكد فرد الى اخر حسب الموقف الهف

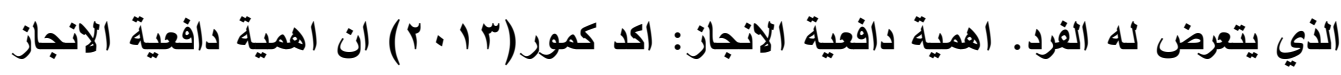

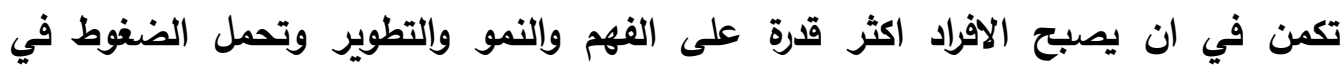

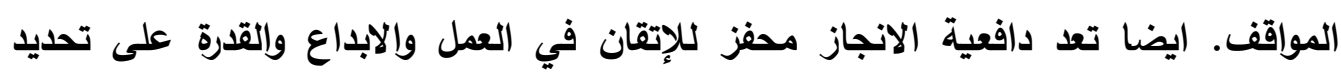

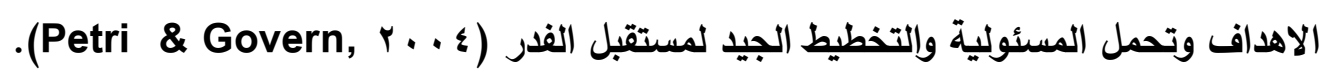

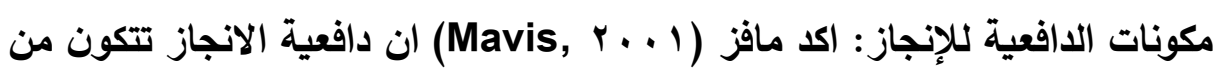
ثلاثة امور كالتالي: 1 - دافع المعرفة: ويتلخص في الشباع الفرد لحاجاته للوصول التول للمعرفة

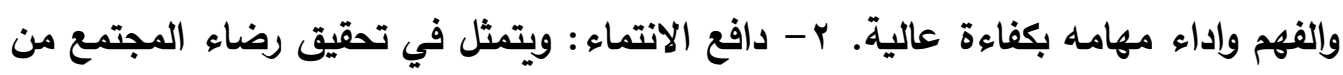

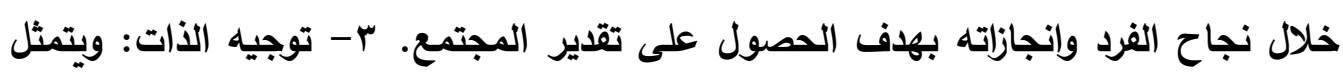

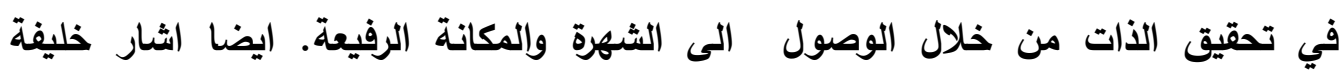

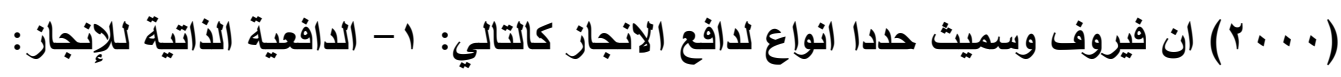

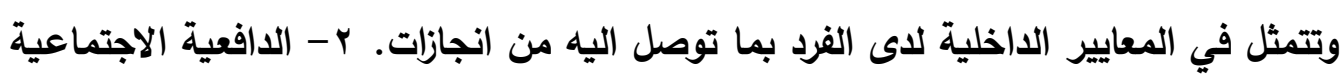
للإنجاز : وتتمثل في اراء المجتمع حيال اداء الفرد ومقارنته بالأخرين.

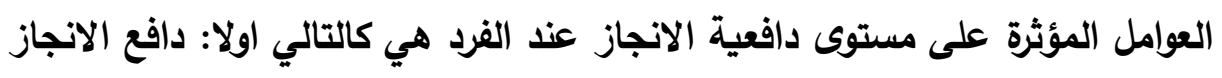

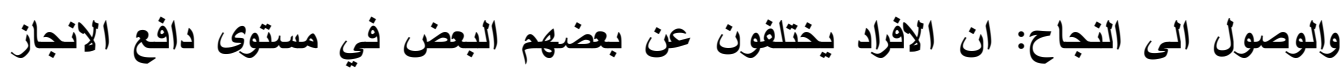

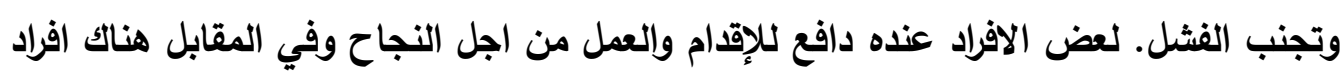

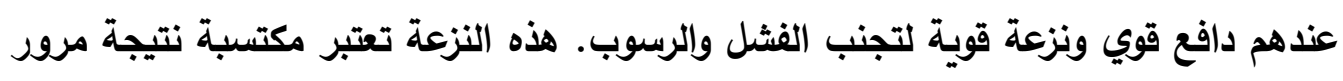

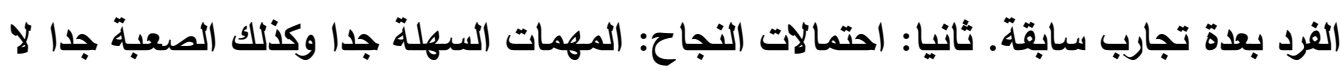


تعطي مؤشر على فرصة المرور بخبرة النجاح. اما المهمة المتوسطة في الصعوبة هي التي تعطي الافراد فرصة المرور بخبرة النجاح والاستفادة منها وكذلك مرور الفرد بمرحلة تحدي الصعوبات. في هذه المهمة تتضح الفروق بين الافراد جليا. ثالثا: القيمة التي تعبر عن باعث النجاح: يعتبر النجاح حافز على العمل والمثابرة باجتهاد فاذا حصل الفرد على درجات عالية في الاختبارات السابقة لمادة معينة فان ذلك يعتبر حافز لله للحصول على درجات مرتفعة في الاختبارات اللاحقة. لنفس المادة (ع . . Petri, H ; and Govern, J, Y). النظريات المفسرة لدافعية الانجاز: اولا نظرية اتكنسون (Atkinson) وتسمى ايضا بنظرية دافع التحصيل، حيث ترى ان دافع التحصيل الدراسي مهم جدا للطالب فهو يثير طاقاتهم تجاه الانجازات. كذلك ترى النظرية ان الافراد يحفزهم ويدفعهم وجود اهداف جذابة يستطيعون انجازها (نوفل، 11 إY). ثانيا نظرية ماكليلاند (McClelland): وترى هذه النظرية ان دافعية الانجاز تعتبر سمة وحافز شخصي تتفاوت بين الافراد اعتمادا على رغباتهم وميولهم، ويتأثر دافع الانجاز بالانفعالات العاطفية. كذلك افترض ماكليلاند نوعين من الادفعية للإنجاز كالتالي: ا- الامل في النجاح والذي يعتبر مرتبط بالانفعالات العاطفية الايجابية. r - الخوف من الفشل وهذا النوع مرتبط بالانفعالات السلبية ( P . . Pieper, r). فيما يتعلق بالدراسات السابقة التي اهتمت بالإحباط فقد هدفت دراسة فولكمان (Folkman, r. . r)

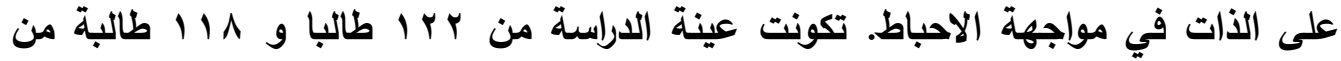
مدرستين بولاية فيرجينيا الامريكية. توصلت الدراسة الى انه كلما زاد مستوى الدافعية الداخلية عند الفرد انخفض مستوى الاحباط، كذلك كلما قل مستوى الدافعية الداخلية للفرد ادى الى ارتفاع مستوى الاحباط عند الفرد. كذلك قام الصرايره (0 . . ب) بدراسة مظاهر الاحباط الوظيفي واثثارها في الاغتراب التنظيمي حيث اجربت الدراسة على المنظمات الصحية العامة في دولة الاردن وذلك على عينة من الاطباء في مختلف التخصصات الطبية حيث بلغ عدد افراد العينة هـ ــ ـ. هدفت الاراسة الى معرفة طبيعة علاقة الارتباط وإلتأثير بين الاطباء المفتربين حيث لوحظ ان هناك زيادة حالات الاحباط مما قد يودي الى زيادة الاغتراب. توصلت الدراسة الى ارتفاع مستويات الاحباط الوظيفي عند افراد عينة الدراسة وكذلك الاغتراب التنظيمي. ايضا توصلت الدراسة الى 
ان الاحباط سبيل للوصول الى الاغتراب التظيمي. كما توصلت الاراسة الى وجود علاقة تأثير معنوية بين الاحباط الوظيفي والاغتراب التنظيمي كذلك توصلت الدراسة الى ان مستويات الاحباط والاغتراب تختلف بين افراد العينة وذلك بحسب اختلاف التخصصات.

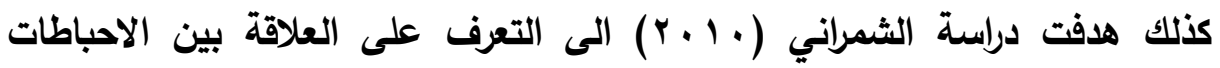
المهنية والدافعية للإنجاز، وتكونت عينة الدراسة من TVY معلما، 101 معلمة في التعليم العام بالمرحلة الابتدائية في مدارس مكة المكرمة، وتوصلت الدراسة إلى ان اهم الاحباطات المهنية التي تواجه المعلمين وإلمعلمات هي: (المصادر الاقتصادية، المصادر الاجتماعية،

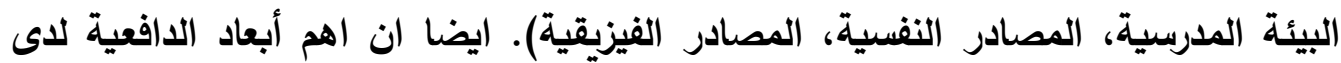
المعلمين والمعلمات حسب الأهمية مرتبة كالتالي: (الثعور بأهمية الزمن - المثابرة المسئولية - التفوق - التخطيط للمستقبل) كذلك توصلت الدراسة الى ان هناك فروق في مستوى الاحباطات المهنية لاى افراد عينة الدراسة من معلمين ومعلمات لصالح المعلمين. وجود فروق ذات دلاله احصائية بين افراد عينة الدراسة وذلك في دافعية الانجاز لصالح المعلمات. وجود علاقة عكسية بين دافعية الانجاز ومستوى الاحباط. بمعنى انه كلما زاد الاحباط عند الفرد ادى الى انخفاض مستوى دافعية كذلك قام ذياب (1 1 ـ Y) بلدراسة قياس مستوى الإحباط لاى طلبة الجامعات، وكذلك التعرف على الفروق بين طلبة الجامعة (الذكور والاناث) في مستوى الاحباط، وتكونت العينة من ه r امن طلبة جامعتي بغداد والمستنصرية بالفرقة الرابعة. توصلت الدراسة ان الطلبة لا يتمتعون بقدر جيد من اشباع الحاجات ومن ثم فهم يعانون من الإحباط، كذلك ان هناك فروق ذات دلالة إحصائية بين متوسطي درجات الأكور والإناث على مقياس الإحباط لصالح الطالبات.

Gulzar, Yahya, ) ايضا اهتمت دراسة جولزار ويحي و نعمان و مير و مجاهد

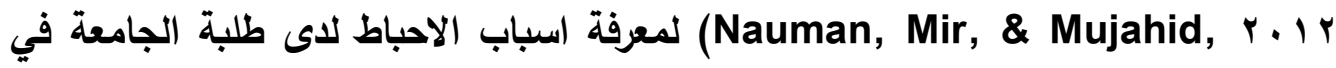

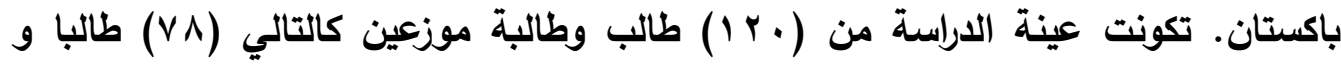
(r ₹ ) طالبة في جامعات مدينة لاهور في باكستان. توصلت الدراسة ان من اسباب الاحباط عند الطلبة يرجع الى فقدان الوالدين. علاوة على ذلك ان من اسباب الاحباط الاكتئاب الأئم و فقدان الاهتمام وكذلك انخفاض مستوى الطالب. 
اما ما يخص الدراسات التي اهتمت بدافعية الانجاز فقد قام كلا من العلي و سحلول

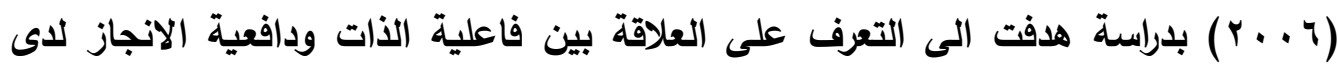
الطلبة وكذلك فحص اثر كل من فاعلية الأات ودافعية الانجاز على التحصيل الدارسي للطلاب

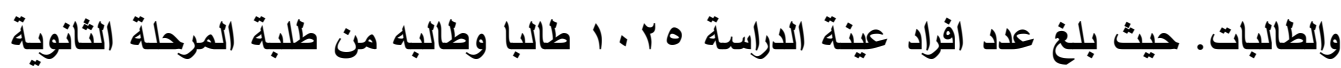
الصف الثاني الثانوي (علمي وادبي) بمدينة صنعاء بدولة اليمن. حيث استخدم الباحثان مقياس فاعلية الأات لثفارتسر وكذلك مقياس دافعية الانجاز للأطفال والراثندين لهيرمانز.

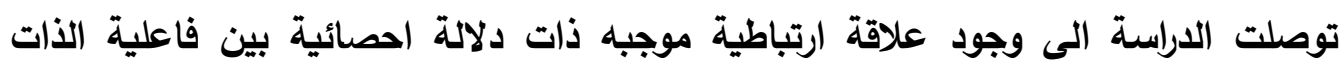

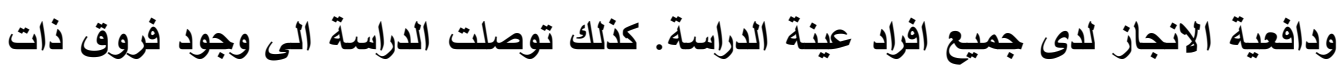

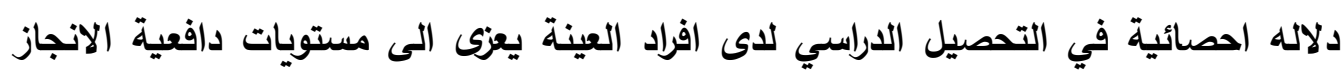

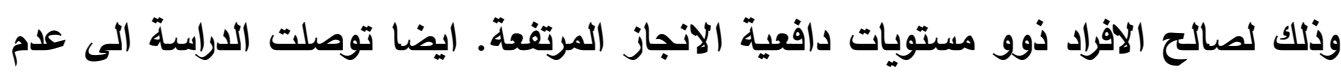

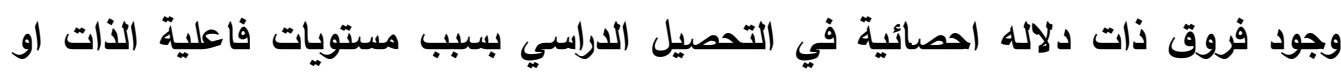
التفاعل بين فاعلية الذات ودافعية الانجاز .

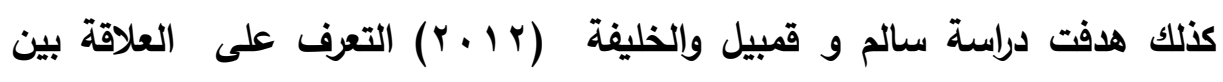

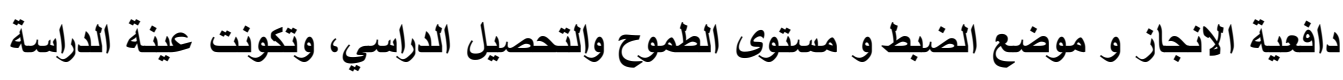

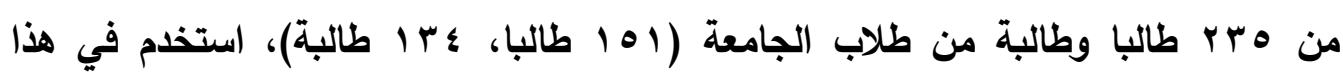

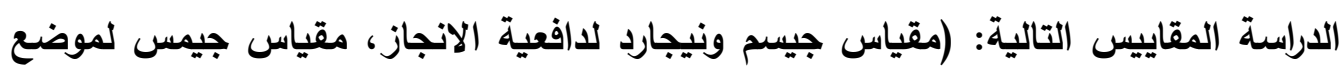

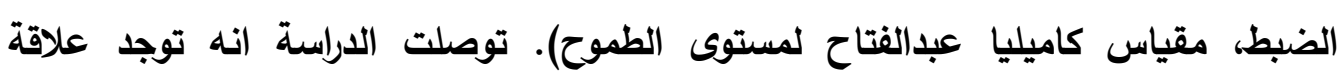

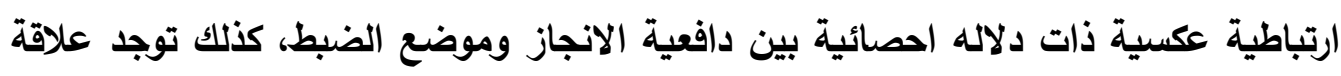

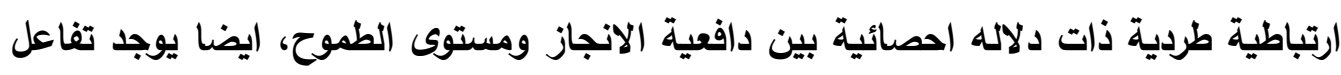

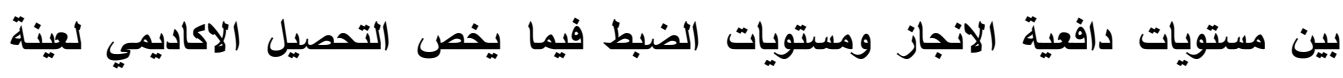

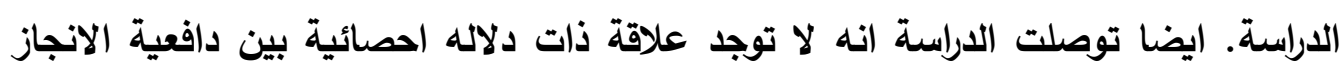
وإلتحصيل الدراسي.

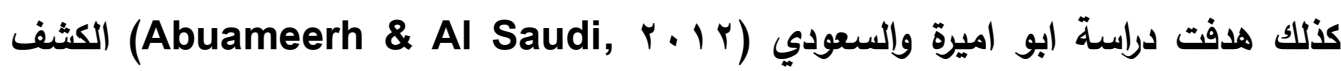

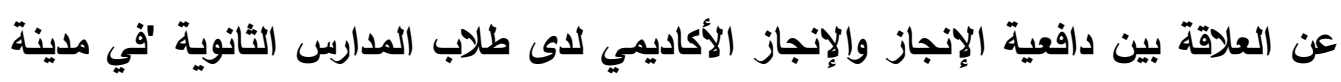

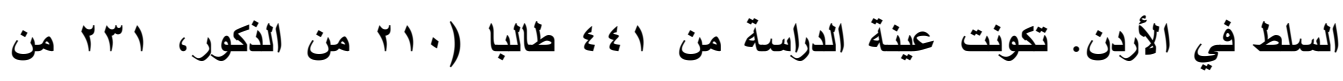

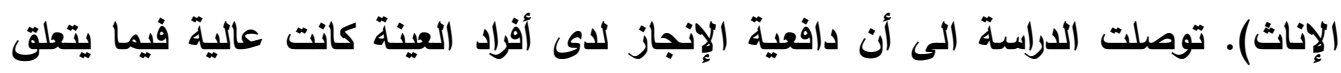


بالأبعاد الرئيسية لدافعية عدا بُعد الطموح فكان الدافع لاى الطلاب أفراد العينة نحوه ضعيف. ايضا توجد فروق ذات دلالة إحصائية بين متوسطي درجات الطلاب الذين تلقوا تحفيز والذين

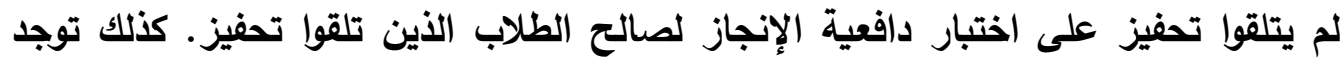
فروق ذات دلالة إحصائية بين متوسطي درجات الطلاب والطالبات على اختبار دافعية الإنجاز لصالح الطلاب.

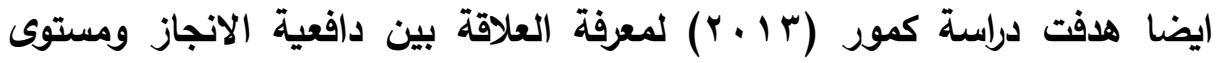

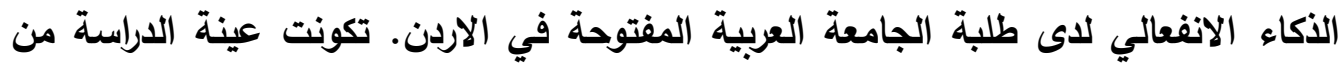

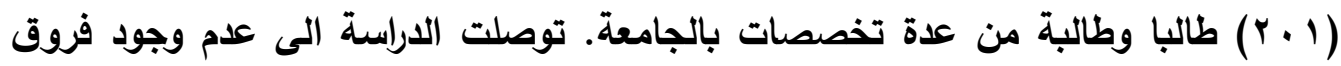
في مستوى دافعية الانجاز تعزى الى التخصص الاكاديمي في الجامعة او النوع, في حين توجد علاقة ارتباطية بين دافعية الانجاز والذكاء الانفعالي. هدفت دراسة اليوسف (1) + ب) الى التعرف على مستوى الدافعية للإنجاز لاى طلبة الجامعة في ضوء النوع والتخصص ومستوى التحصيل الاكاديمي. تكونت عينة الدراسة من VTr ط طالبا وطالبة. توصلت الدراسة الى ان مستوى دافعية الانجاز لاى الطلبة مرتفع لصالح الطالبات، وجود فروق ذات دلالة احصائية في مستوى دافعية الانجاز تعزى لمتفير مستوى التانيا

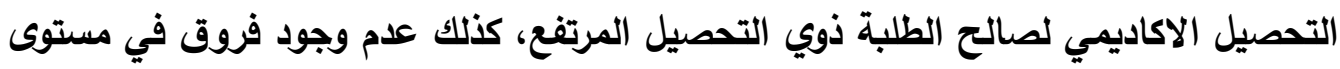
دافعية الانجاز تعزى لمتغير التخصص الاكاديمي. من خلال استعراض الدراسات السابقة نستنتج ما يلي:

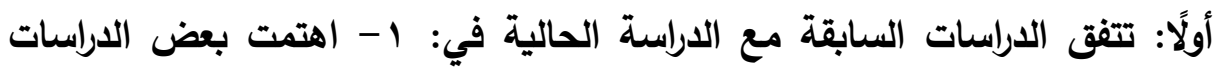

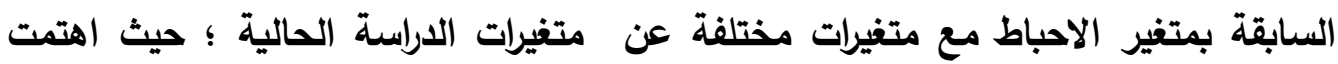

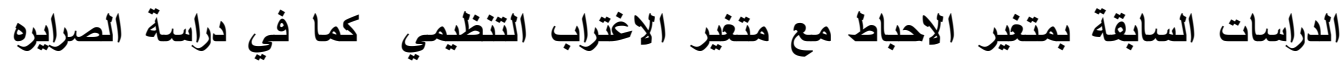

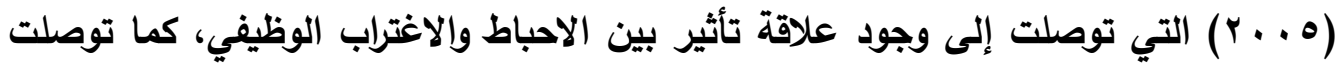

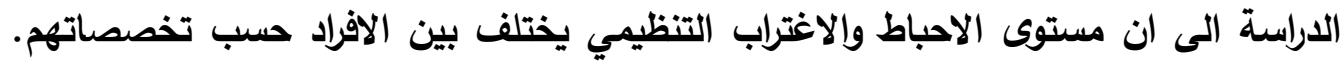
ايضا اهتمت بعض الدراسات بمعرفة العلاقة بين الاحباطات المهنية والدافعية للإنجاز مثل

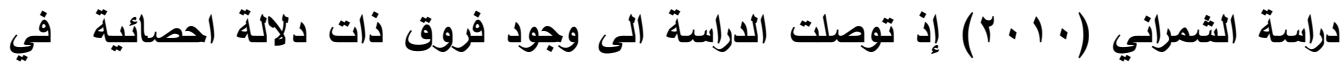

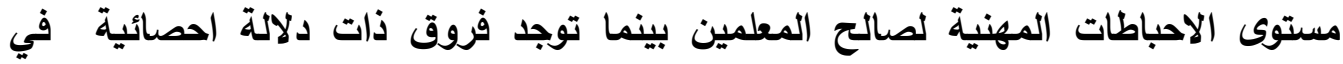
دافعية الانجاز لصالح المعلمات. وجود علاقة عكسية بين الاحباط ودافعية الانجاز. كذلك 
اهتمت دراسة الذياب (11 + (1) لمعرفة مستوى الإحباط لاى طلبة الجامعات، وكذلك معرفة الفروق بين طلبة الجامعة في مستوى الاحباط، وتوصلت الدراسة الى ان مستوى الاحباط لاى الطلبة كان منخفضا لصالح الطالبات. ب - اهتمت بعض الدراسات السابقة بمتغير دافعية الدية الانجاز مع متغيرات مختلفة عن متغيرات الدراسة الحالية، حيث اهتمت بعض الدراسات

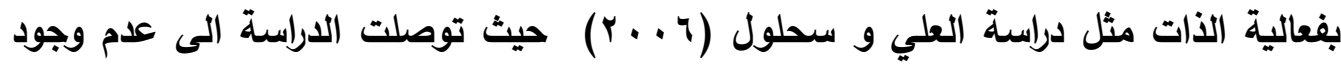
فروق في التحصيل الدراسي بسبب مستويات فاعلية الذات او التفاعل بين فاعلية الذات ودافعية الانجاز. كذلك اهتمت بعض الدراسات بمتغير دافعية الانجاز مع موضع الضبط ومستوى الطموح والتحصيل الدراسي والانجاز الاكاديمي كما في دراسة سالم و قمبيل و

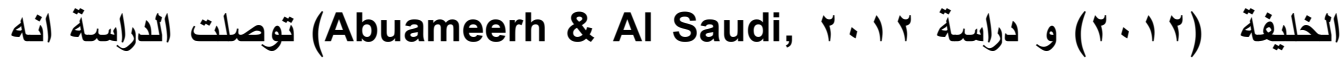
يوجد تفاعل بين مستويات دافعية الانجاز ومستويات الضبط فيما يخص التحصيل الاكاديمي كذلك توجد علاقة ارتباطية طردية ذات دلاله احصائية بين دافعية الانجاز ومستوى الطموح. كذلك توصلت الدراسة انه توجد فروق بين متوسطي درجات الطلبة الذين تلقوا تحفيز على دافعية الإنجاز لصالح الطلاب الذين تلقوا تحفيز. كذلك اهتمت بعض الدراسات بدافعية الانجاز مع النوع والتخصص ومستوى التحصيل مثل دراسة اليوسف (1 ا • ب) ودراسة كمور

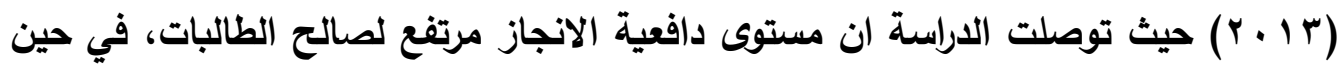
لا توجد فروق في دافعية الانجاز تعزى الى اختلاف التخصص الاكاديمي.

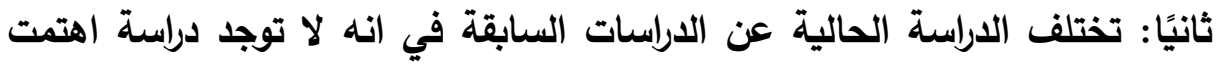
بمتغيرات الدراسة الحالية على حد علم الباحث في حين توجد دراسة اهتمت بمتغير الاحباط

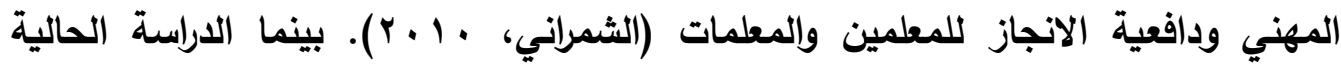
طبقت على طلاب الجامعة الذين لم يسبق لهم التوظيف مما يميز الدراسة الحالية بالأصالة والحداثة في البحث. مشكلة الدراسة: تبلورت مشكلة الدراسة من خلال مراجعة الاراسات السابقة والأدب التربوي المتعلق بالإحباط ودافعية الانجاز وعلاقتهما بالتحصيل الاكاديمي لدى طلاب الداب الكلية الجامعية بالجموم (كلية المعلمين سابقا) حيث كانت الكلية سابقا تتبع اداريا وزارة المعارف لذلك كان توظيف خريجي الكلية مباشرة من الوزارة, اما حاليا فالكلية تتبع جامعة ام القرى والتوظيف 
يتم عن طريق وزارة الذدمة المدنية و حسب اشتراطات الوزارة وتوفر الوظائف الثاغرة قد يكون عائق على الطلاب الخرجين من الكلية الحصول على الوظيفة مما يؤثر على مستوى الاحباط لاى الطلاب في الكلية. حيث اكلت الدراسات السابقة والأدب التربوي تأثير عامل

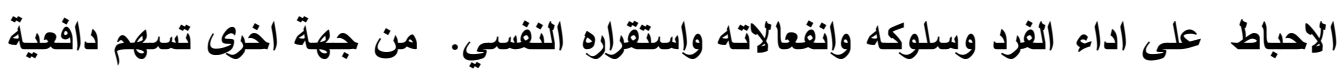
الانجاز في تحقيق اهداف الفرد وغاياته بكفاءة ومواجهة التحديات التي يتعرض لها في في سبيل الوصول للنجاح وتقدير المجتمع من جهة ومن جهة اخرى تجنب الفشل واللوم. وبناءً على استعراض الدراسات السابقة وفي ظل غياب الدراسات التي تعالج ظاهرتي الإحباط ودافعية الانجاز وعلاقتهما بالتحصيل الاكاديمي لاى طلاب الكلية الجامعية بالجموم التابية

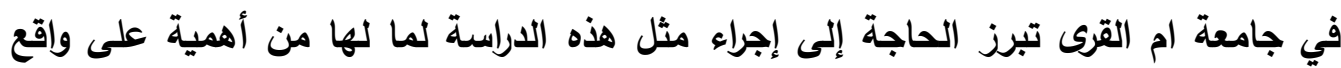
العملية التربوية، لذلك جاءت هذه الدراسة لتسلط الضوء على الإحباط ودافعية الانجاز وعلاقتهما بالتحصيل الاكاديمي لاى طلبة الكلية الجامعية بالجموم في جامعة أم القرى.

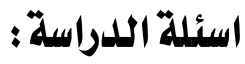

الاراسة الحالية تسعى إلى الإجابة عن الأسئلة التالية:

ما مستوى الاحباط لاى طلاب الكلية الجامعية بالجموم في جامعة أم القرى؟ الإبه

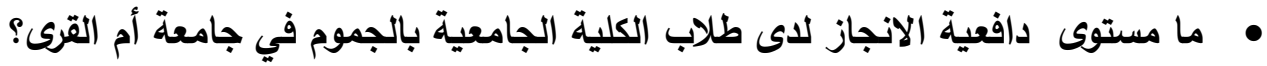
• هل توجد فروق ذات دلالة احصائية بين تخصص الطلاب (رياضيات - لغة عربية)

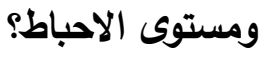
• هل توجد فروق ذات دلالة احصائية بين تخصص الطلاب (رياضيات - لغة عربية) ومستوى دافعية الانجاز؟ هل توجد علاقة ارتباطية بين مستوى الاحباط والتحصيل الاكاديمي لاى افراد عينة الاراسة؟ هل توجد علاقة ارتباطية بين مستوى دافعية الانجاز والتحصيل الاكاديمي لدى افراد عينة الدراسة؟ هل توجد علاقة ارتباطية بين مستوى الاحباط لاى افراد عينة الدراسة ومستوى

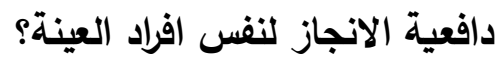




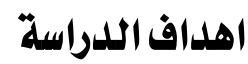

1- التعرف على مستوى الاحباط لاى طلاب الكلية الجامعية بالجموم. r- التعرف على مستوى دافعية الانجاز لاى طلاب الكلية الجامعية بالجموم. r- الكثف عن الفروق بين تخصص الطلاب (عينة الاراسة) و مستوى الاحباط. ؟- التعرف عن الفروق بين تخصص الطلاب (عينة الدراسة) و مستوى دافعية الانجاز

ه- الكثف عن العلاقة بين مستوى الاحباط والتحصيل الاكاديمي لاى افراد عينة الدراسة

צ- التعرف على العلاقة بين مستوى دافعية الانجاز وإلتحصيل الاكاديمي لاى افراد

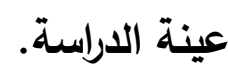

- V الكثف عن العلاقة بين مستوى الاحباط ومستوى دافعية الانجاز لاى افراد عينة

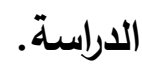

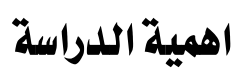

تكمن أهمية الدراسة الحالية من خلال توظيف نتائج الدراسة نظريًا وتطبيقيًا، من

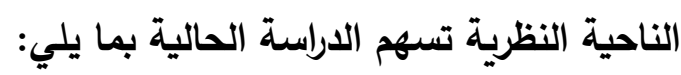

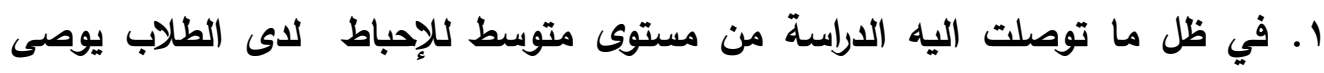

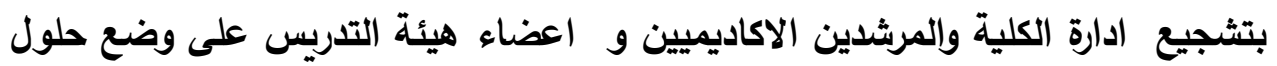
لاحتواء مشكلة الاحباط.

r. حث الباحثين على تناول هذه المشكلة من عدة زوايا وذلك بما يفيد المجتمع السعودي. r. من خلال ما توصلت اليه الدارسة من علاقة عكسية بين الاحباط ودافعية الانجاز يوصى بالحد من كل مسببات الاحباط عند الطلاب وذلك لزيادة دافعية انجازهم.

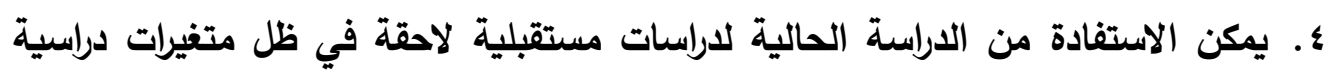
جديدة.

أما ما يتعلق بأهمية الدراسة تطبيقياً فيمكن أن تسهم الدراسة الحالية بما يلي: 1. تعتبر الدارسة الحالية احد أدوات البحث العلمي التي يستفاد منها للاراسات الحديثة. 
r. التثجيع على عقد الدورات التدريبية والندوات حول الاحباط و دافعية الانجاز لاى طلبة

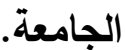

r. من منطلق اهمية الدراسة الحالية قلة الداسات على مستوى المملكة العربية السعودية التي اهتمت بمتغيرات الدراسة الحالية.

مصطلحات الدراسة

الاحباط (Frustration): يعرف الاحباط بانه عبارة عن "حالة انفعالية يرافقها

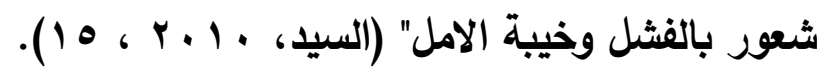

ويعرف الاحباط اجرائيا: بالدرجة التي يحصل عليها الفرد في مقياس الاحباط

$$
\text { الأني اعده الباحث }
$$

دافعية الانجاز (Achievement Motivation): تعرف بانها ثبات نسبي في

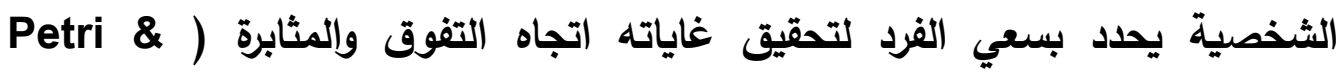
.(Govern, r. . \&

وتعرف دافعية الانجاز اجرائيا: الدرجة التي يحصل عليها الفرد في مقياس دافعية الانجاز الذي اعده الباحث. التحصيل الاكاديمي (Academic Achievement): ويشير الى انجازات الطلاب خلال الفصل الدراسي ويعبر عنه بالمعل التراكمي لدرجات افراد العينة خلال

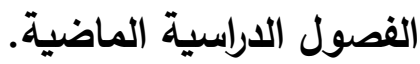

\section{حدود الدراسة}

تتحدد نتائج الدراسة بالحدود التالية: • الحدود الموضوعية: تتحدد الدراسة الحالية بموضوع الاحباط من قلة التوظيف ودافعية

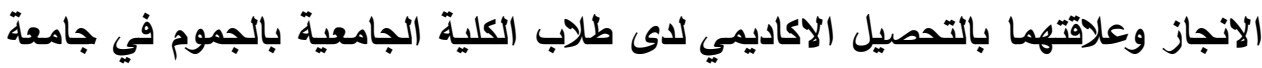

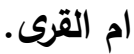

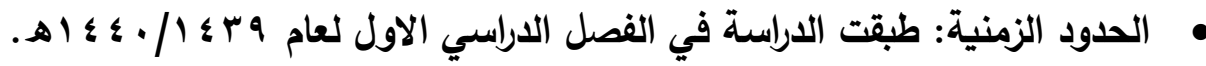

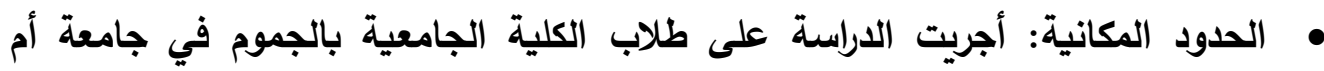




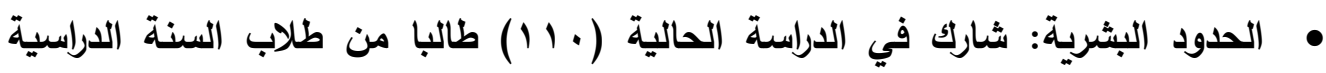

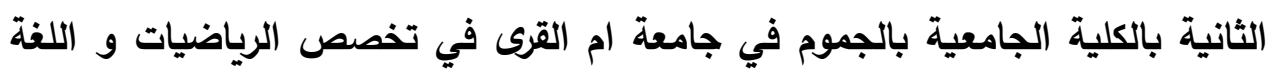
عربية.

الحدود الأدائية: حدد الداسة الحالية بمقياسي الاحباط ودافعية الانجاز من إعداد

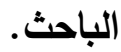

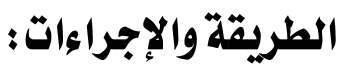

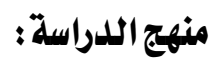

انطلاقا من طبيعة الدراسة واهدافها وتساؤلاتها فقد اعتمد الباحث المنهج الوصفي

الارتباطي المقارن وذلك لمناسبته للاراسة.

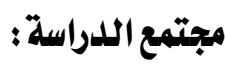

يتكون مجتمع الدراسة من جميع طلاب السنة الدارسية الثانية في الكلية الجامعية

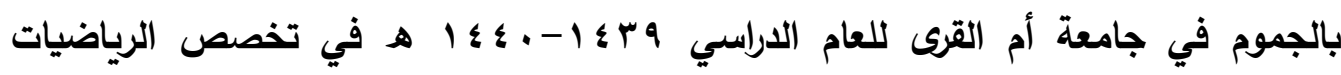

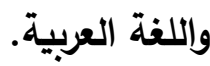

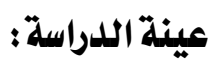

اشتملت عينة الدارسة الحالية على (•11) طالبا من العنه الاراسية الثانية بالكلية

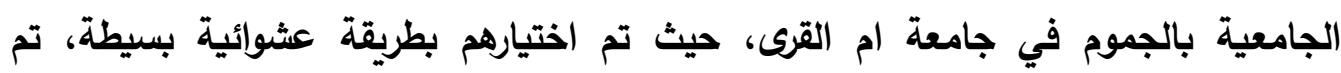

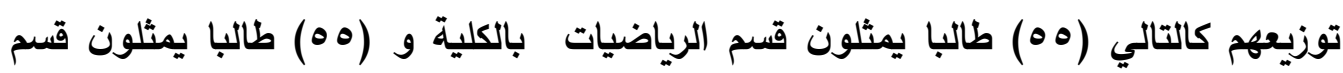

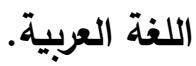

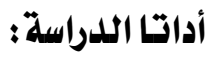

استخدم الباحث في الدارسة الحالية مقياسين هما:

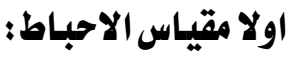

بناءً على اطلاع الباحث على الدارات السابقة والمقاييس التي اهتمت بالإحباط

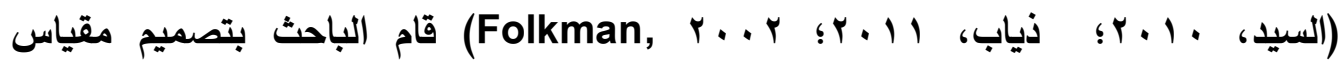
للاحباط. 
وصف المقياس

يتكون المقياس من قسمين: القسم الاول عبارة عن معلومات عامة عن المفحوص اما القسم الثاني من المقياس فعبارة عن (9 1) فقرة تهتم بقياس مستوى الاحباط لاى منى

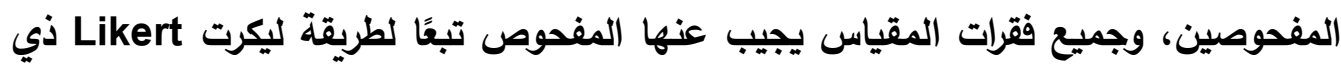
خمسة بدائل ( لا ينطبق على، ينطبق على نادرًا، ينطبق على أحيانًا ، ينطبق على غالبًا ، وينطبق على تمامًا ) يعطى المفحوص درجة تتراوح بين (1-ه) على الترتيب لفقرات

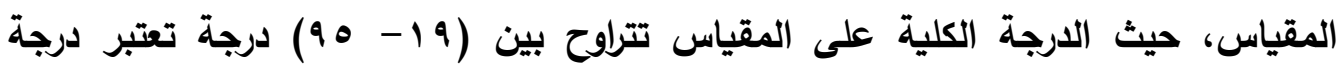
المفحوص المرتفعة في المقياس مؤشرًا على الاحباط، وقد اعتمد الباحث المعيار الإحصائي

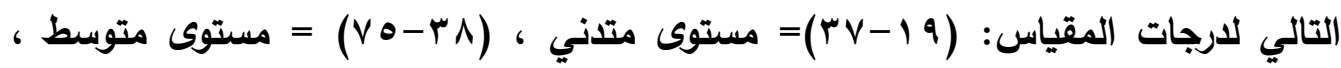
( $(90-V \uparrow)$

الخصائص السيكومترية لمقياس الاحباط: صدق المقياس: 1- صدق المحكمين: جرئ إيجاد صدق المحكمين للمقياس وذلك بعد عرضه على مجموعة

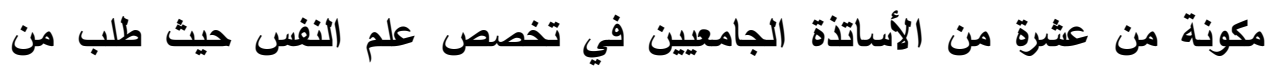
المحكمين التأكد من مدى انتماء كل فقرة للمقياس، ومدى وضوح كل فقرة ومناسبتها وصياغتها اللغوية ، وكذلك التأكد من مدى مناسبة المقياس لعينة الدراسة وإبداء أي ملاحظات يرونها مناسبة للمرحلة الدراسية، وتم الأخذ بملاحظات المحكمين وقد تم من ماعيه

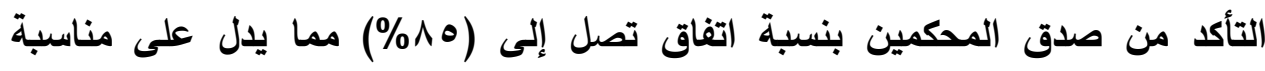
المقياس لقياس الاحباط لاى طلبة الكلية الجامعية بالجموم. r- صدق الاتساق الداخلي: جرئ إيجاد صدق الاتساق الداخلي لمقياس الاحباط لمعرفة مدى صدق المفردات، عن طريق حساب معاملات الارتباط بين كل فقرة من فقرات

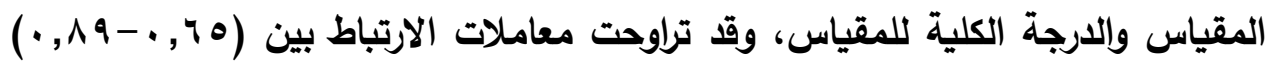
مما يدل على أنه توجد ارتباطات دالة إحصائيًا بين فقرات المقياس واللارجة الكلية للمقياس, وهذا يعكس الاتساق و صدق المقياس. 
ثبات المقياس:

تم التأكد من ثبات مقياس الاحباط عن طريق اعادة الاختبار على عينة استطلاعية

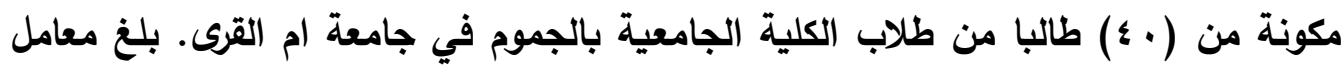
الارتباط بين التطبيقين ( •^، •) وذلك بعد بفاصل زمني مدته ثلاث اسابيع، وهذه النتيجة تدل على صلاحية وثبات المقياس على البيئة السعودية. ثانيا مقياس دافية الانجاز: قام الباحث من خلال الادبيات والدراسات السابقة التي اهتمت بدافعية الانجاز

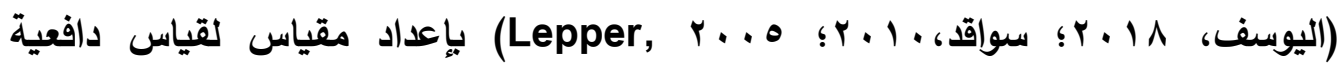
الانجاز لاى طلاب الكلية الجامعية بالجموم. وصف المقبـاس يتكون المقياس من قسمين: القسم الاول عبارة عن معلومات عامة عن المفحوص

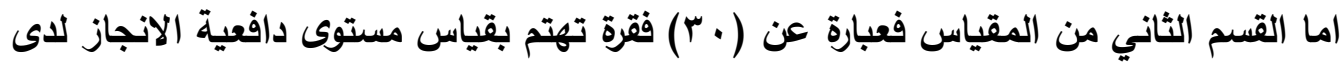
المفحوصين، وجميع فقرات المقياس يجيب عنها المفحوص تبعًا لطريقة ليكرت Likert ذي

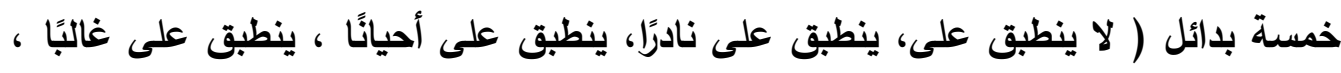
وينطبق على تمامًا ) يعطى المفحوص درجة تتراوح بين (1-ه) على الترتيب لفقرات

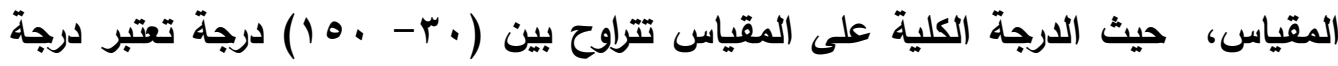
المفحوص المرتفعة في المقياس مؤشرًا على ارتفاع مستوى دافعية الانجاز، وقد اعتمد

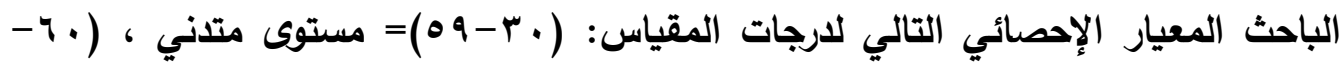

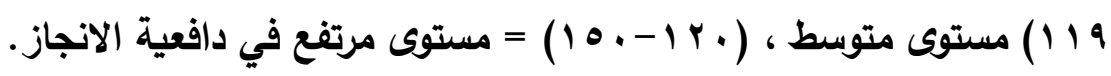

الخصائص السيكومترية لمقياس دافية الانجاز:

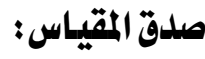
• صدق المحكمين: جرئ إيجاد صدق المحكمين للمقياس وذلك بعد عرضه على مجموعة مكونة من عشرة من الأساتذة الجامعيين في تخصص علم النفس حيث طلب من المحكمين التأكد من مدى انتماء كل فقرة للمقياس، ومدى وضوح كل فقرة ومناسبتها وصياغتها اللغوية ، وكذلك التأكد من مدى مناسبة المقياس لعينة الدراسة وإبداء أي ملاحظات يرونها مناسبة للمرحلة الدراسية، وتم الأخذ بملاحظات المحكمين وقد تم 
التأكد من صدق المحكمين بنسبة اتفاق تصل إلى (^^v) مما يدل على مناسبة المقياس لقياس دافعية الانجاز لاى طلبة الكلية الجامعية بالجموم. صدق الاتساق الداخلي: جرئ إيجاد صدق الاتساق الداخلي لمقياس دافيعية الانجاز

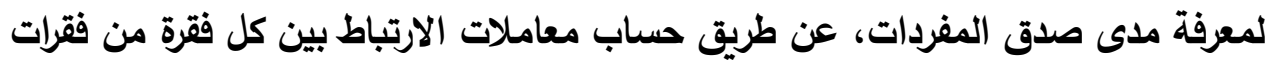

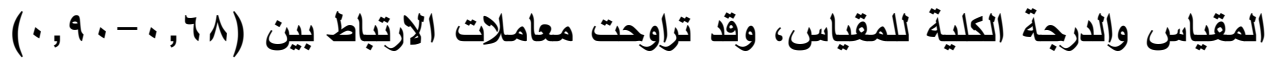

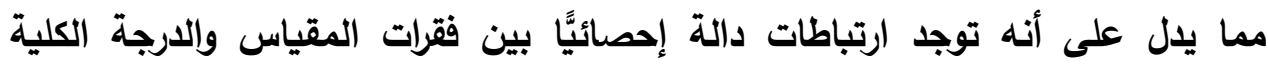
للمقياس, وهذا يعكس الاتساق و صدق المقياس.

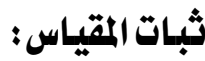

تم التأكد من ثبات مقياس دافعية الانجاز عن طريق اعادة الاختبار على عينة استطلاعية مكونة من (· ؛) طالبا من طلاب الكلية الجامعية بالجموم في جامعة ام القرى.

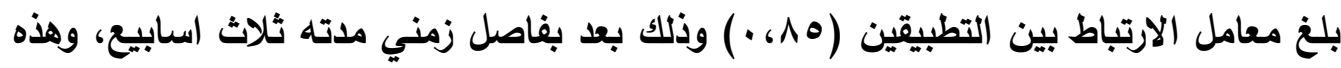
النتيجة تدل على صلاحية وثبات المقياس على البيئة السعودية.

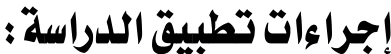

1-بناء مقياسين في الدراسة الحالية وهما: الاحباط ود/فعية الانجاز، والتحقق من الخصائص السيكومترية لهما. r - برض مقياسي الداسة على المحكمين. ب- إجراء التعديلات المقترحة من قبل المحكمين.

؛ - اختيار العينة الاستطلاعية عشوائيًا لإجراء الخصائص السيكومترية لأداتي الاراسة.

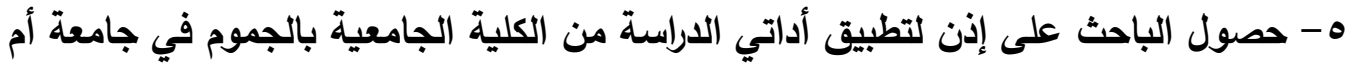
القرى.

4- اختيار عينة الدراسة بطريقة عشوائية بسيطة.

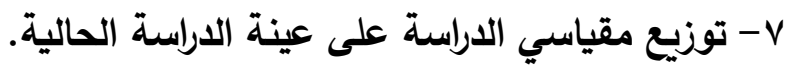
1- تم استخام الرزم الإحصائية للعلوم الاجتماعية لإجراء التحليلات الإحصائية اللازمة. 


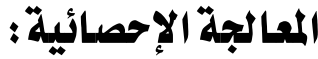

للإجابة عن أسئلة الاراسة الحالية جرئ استخدم الأساليب الإحصائية التالية: • المتوسطات الحسابية والانحرافات المعيارية للإجابة عن سؤالي الدراسة الأول والثاني. • اختبار ت لمعرفة الفروق بين افراد العينة فيما يخص تخصص الطلاب (رياضيات- لغة لغابلة عربية) ومتغيرات الدراسة وذلك للإجابة على السؤال الثالث والرابع. • معامل ارتباط بيرسون للإجابة عن السؤال الخامس والسادس والسابع.

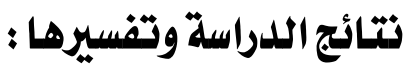

تتائج السؤال الأول وتفسيرها: والذي ينص على: "ما مستوى الاحباط لاى طلاب

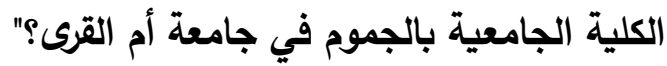
للإجابة عن السؤال الأول جرئ حساب المتوسطات الحسابية والانحرافات المعيارية لارجات

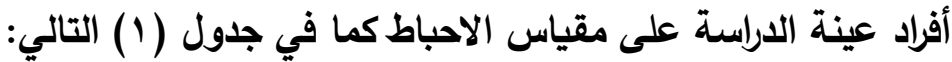

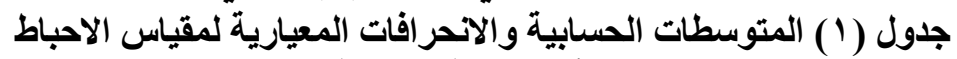

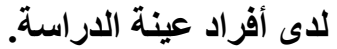

\begin{tabular}{|c|c|c|c|c|}
\hline مستوى الاحباط & الانحر اف المعياري & المتوسط الحسابي & العدد & التخصص \\
\hline متوسط & $9 . \leqslant 4$ & $\{. .1 \leqslant$ & 00 & رياضيا \\
\hline متوسط & $\Lambda . \vee 9$ & $7 V . q \varepsilon$ & 00 & لغة عربية \\
\hline متوسط & 17.74 & $0 \leqslant$ & 11. & المجموع \\
\hline
\end{tabular}

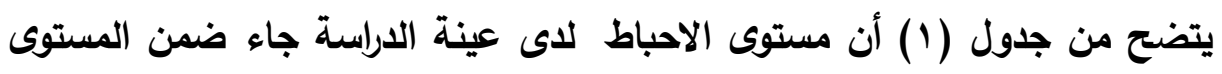
المتوسط, واللبب في ذلك يرجع الى ان طلاب الكلية الجامعية (كلية المعلمين سابقا) في

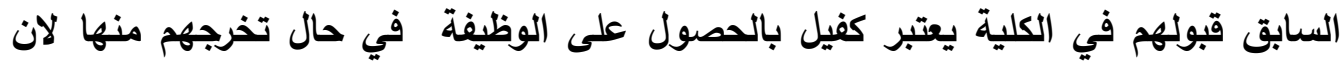

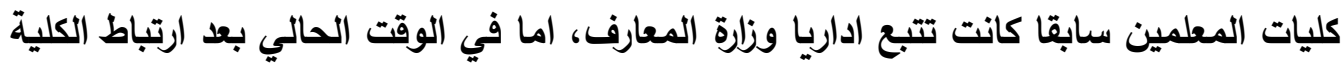

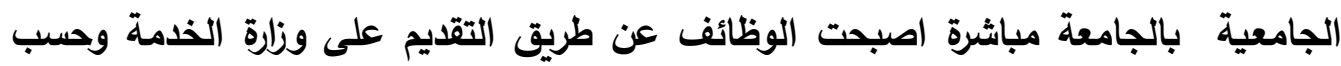
الاحتياج وكذلك اجتياز اختبار القدرات للمعلمين مما قد يسبب عائق لبعض الطلاب

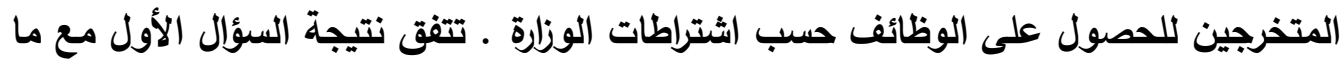

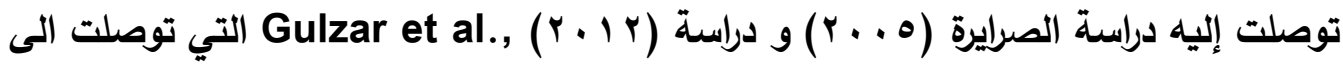
ان مستوى الاحباط كان مرتفعا لاى الافراد ويرجع ذلك الى ان الناحية المعنوية وفقدان

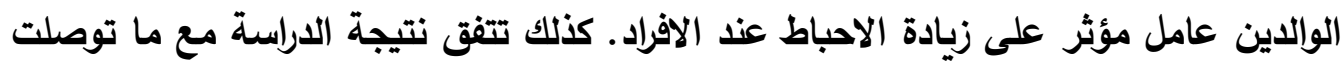


اليه دراسة ذياب (11 + ؟ ان مستوى الاحباط بين الطلاب كان مرتفعا نسبيا اما الطالبات فكان منخفضا والسبب في ذلك يرجع الى ان عدم اشباع الحاجات النفسية لها دور اساسي في الارتفاع من مستوى الاحباط لاى الافراد. نتائج السؤال الثاني وتفسيرها: والذي ينص على: "ما مستوى دافعية الانجاز لاى الدى

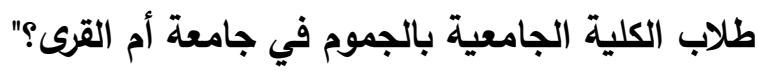
للإجابة عن السؤال الأول جرئ حساب المتوسطات الحسابية والانحرافات المعيارية لارجات

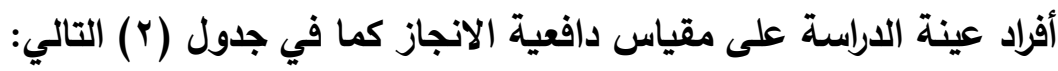

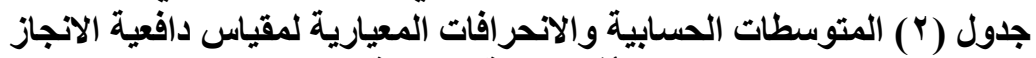
لاى أفراد عينة الدراسة.

\begin{tabular}{|c|c|c|c|c|}
\hline مستوى الاحباط & الانحراف المعياري & المتوسط الحسابي & العدد & التخصص \\
\hline متوسط & $9 . r 9$ & 91.01 & 00 & رياضيات \\
\hline متوسط & 9.07 & $91 . \leqslant 9$ & 00 & لفة عربية \\
\hline متوسط & $9 . \leqslant r$ & 91.00 & 11. & المجموع \\
\hline
\end{tabular}

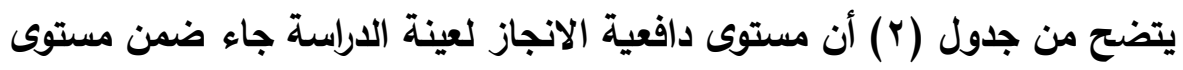

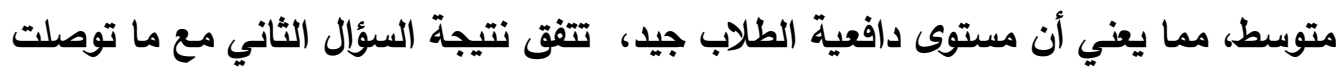

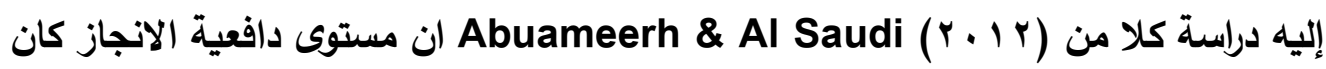

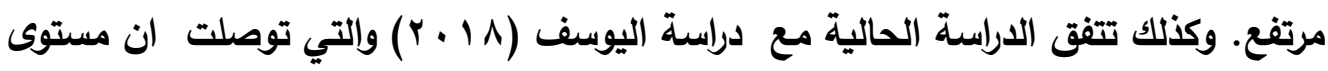
دافعية الانجاز لاى الافراد كان مرتفعا.

نتائج السؤال الثالث وتفسيرها : والذي ينص على "هل توجد فروق ذات دلالة احصائية بين مستوى الاحباط وتخصص الطلاب؟

للإجابة عن السؤال الثالث قام الباحث بحساب المتوسطات الحسابية والانحرافات المعيارية ومستوي الدلالة وذلك باستخدام اختبار ت. الجدول (r) يوضح نتيجة السؤال الثالث.

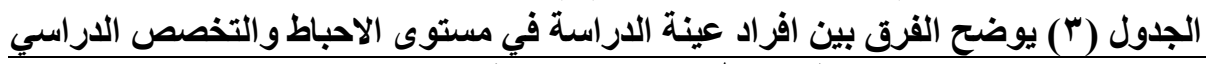

\begin{tabular}{|c|c|c|c|c|c|}
\hline مستوى الدلاية & ت & المعياري & الحستوسي & العدد & التخصص \\
\hline \multirow{3}{*}{$\because \cdot 1$} & & 9.87 & $\varepsilon \cdot .1 \leqslant$ & 00 & رياضيات \\
\hline & $r \varepsilon .+1$ & ^.Vq & $9 V .9 \varepsilon$ & 00 & لغة عربية \\
\hline & & 17.77 & $0 \leqslant .$. & 11. & المجموع \\
\hline
\end{tabular}

يتضح من الجدول (ץ) انه توجد فروق ذات دلاله احصائية عند مستوى (1 (...) 
قسم الرياضيات وطلاب قسم اللغة العربية في مستوى الاحباط وذلك لصالح طلاب قسم اللغة

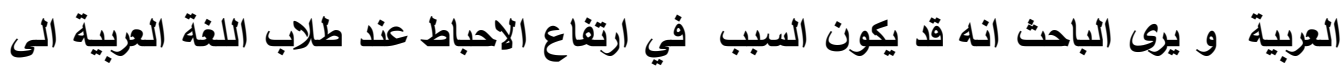
قلة وعي بعض الطلاب واعتقادهم ان مجال اللغة العربية في التوظيف اقل حظا مقارنة بالرياضيات كذلك عدم ارتباط الكلية الجامعية بوزارة التعليم كان لله اثر على زيادة الاحباط

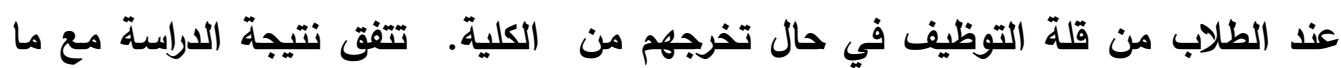
توصلت اليه دراسة الصرايرة (ه . . ب) في ان مستوى الاحباط يختف باختلاف تخصص الافراد.

نتائج السؤال الرابع وتفسيرها: والذي ينص على " هل توجد فروق ذات دلالة

$$
\text { احصائية بين مستوى دافعية الانجاز وتخصص الطلاب؟ }
$$

للإجابة عن السؤال الرابع قام الباحث بحساب المتوسطات الحسابية والانحرافات المعيارية

ومستوي الدلالة وذلك باستخدام اختبار ت. الجدول ( ؛ ) يوضح نتيجة السؤال الرابع.

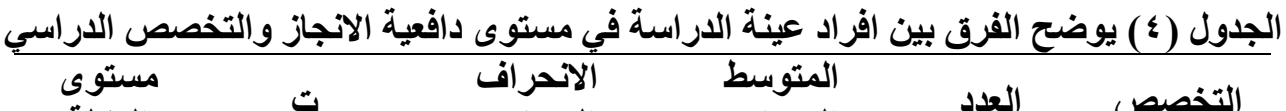

\begin{tabular}{|c|c|c|c|c|c|}
\hline الدلالة & 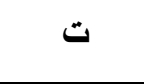 & المعياري & الحسابي & العدد & التخصص \\
\hline \multirow{3}{*}{$\because \cdot 1$} & & 9.19 & 91.01 & 00 & رياضيات \\
\hline & 1.1 .21 & 9.07 & $91 . \leqslant 9$ & 00 & لغة عربية \\
\hline & & $9 . \leqslant \%$ & 91.0. & 11. & المجموع \\
\hline
\end{tabular}

يتضح من الجدول (؛ ) انه لا توجد فروق ذات دلاله احصائية عند مستوى (1 ( ...) بين طلاب قسم الرياضيات وطلاب قسم اللفة العربية في مستوى دافعية الانجاز وهذه النتيجة

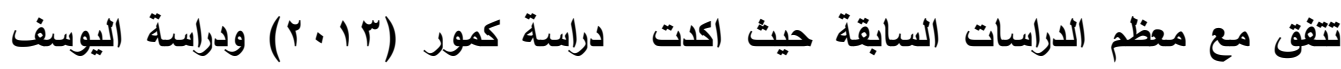

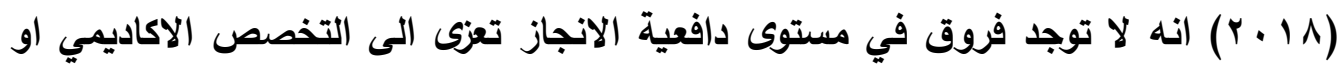
النوع. تتائج السؤال الخامس وتقسيرها : والذي ينص على "هل توجد علاقة ارتباطية بين مستوى الاحباط والتحصيل الاكاديمي لاى افراد عينة الدراسة ؟ للإجابة عن هذا السؤال تم استخراج معامل ارتباط بيرسون بين مستوى الاحباط وإلتحصيل

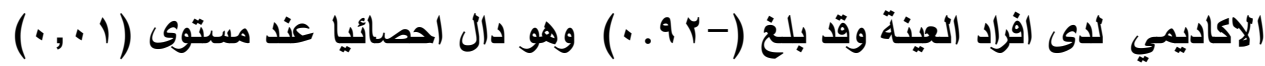
تشير هذه النتيجة الى وجود ارتباط عكسي (سلبي) بين مستوى الاحباط والتحصيل الدراسي بمعنى انه كلما زاد الاحباط عند الفرد قل مستوى التحصيل الاكاديمي والعكس صحيح. تتفق 
ما توصلت حيث اكلت انه توجد علاقة عكسية بين الاحباط والتحصيل Folkman التحصيل الداسي للطلاب لما يسببه من ضعف واهمال في المستوى التدريسي للطالب. تتائج السؤال السادس وتفسيرها: والذي ينص على "هل توجد علاقة ارتباطية بين

مستوى دافعية الانجاز والتحصيل الاكاديمي لاى افراد عينة الاراسة ؟

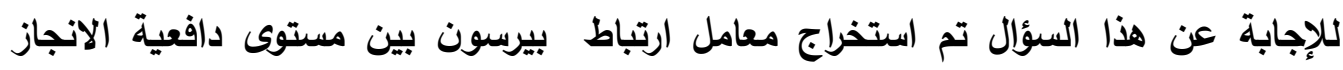

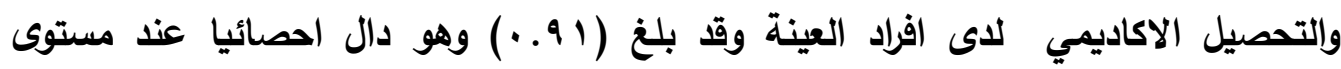
(1. (·) تثير هذه النتيجة الى وجود ارتباط ايجابي قوي بين دافعية الانجاز والتحصيل

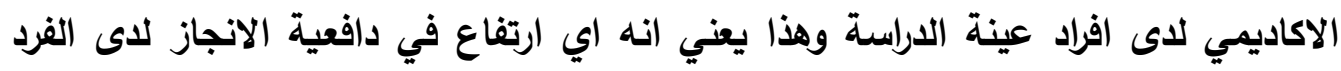

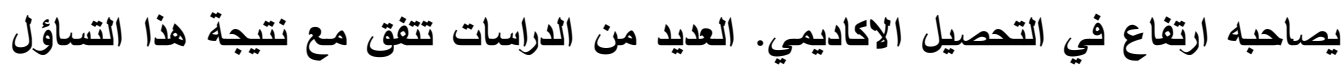

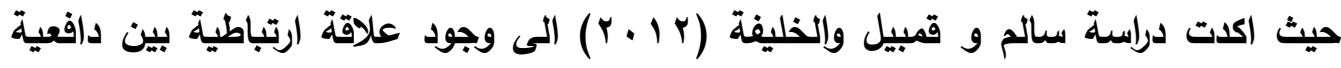

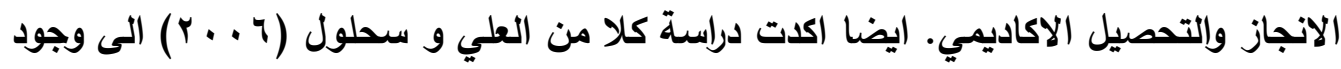

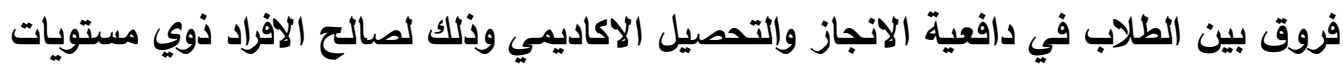

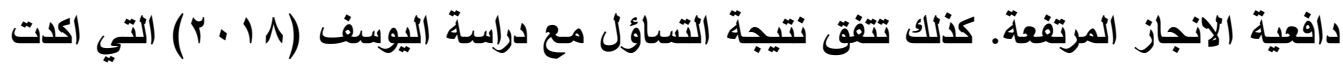

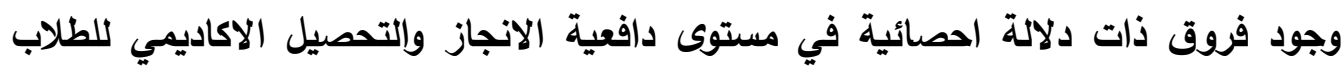
لصالح الطلبة ذوي التحصيل الاكاديمي المرتفع. نتائج السؤال السابع وتفسيرها: والذي ينص على "هل توائ توجد علاقة ارتباطية بين الاحباطو دافعية الانجاز لاى افراد عينة الاراسة ؟ للإجابة عن هذا السؤال تم استخراج معامل ارتباط بيرسون بين الاحباط و دافعية

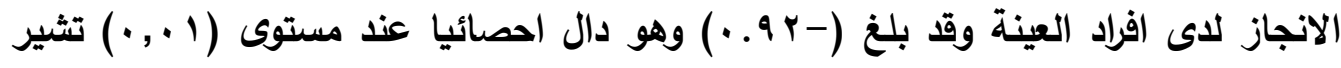

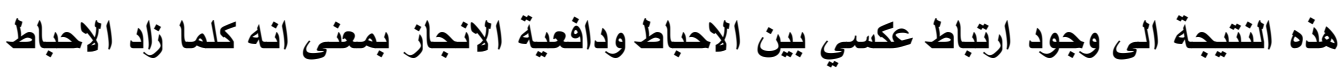

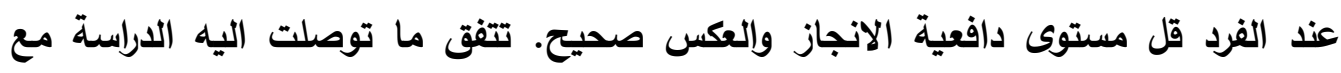

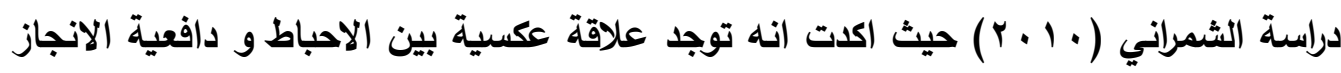

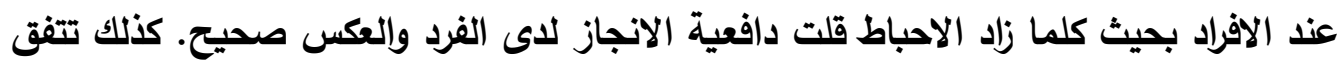

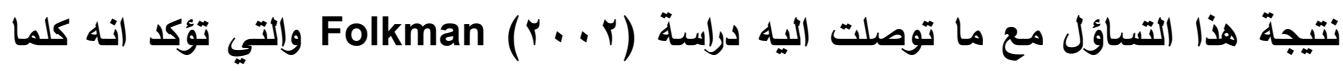


Gulzar et al., زادت الدافعية لاى الفرد قل مستوى الاحباط عنده. ايضا توصلت دراسة

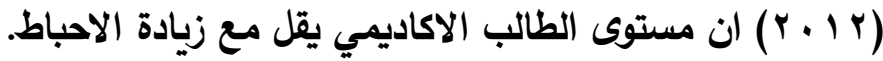

\section{توصيات الدراسة}

• نظرا لان مستوى كلا من الاحباط و دافعية الانجاز متوسطا لذا توصي الدراسة القائمين على العملية التعليمية في الكلية الجامعية بالجموم والمرشدين الاكاديميين على القامة الجارية الندوات التثقيفية للطلاب.

نظرا انه توجد علاقة ارتباطية عكسية بين الاحباط ودافعية الانجاز لذا توصي الدراسة بإقامة البرامج التدريبية والتثقيفية للحد من الاحباط و في نفس الوقت تحفيز الطلاب ودفعهم نحو الانجاز والتفوق. اللدراسات والبحوث المقتزحة : • اجراء دراسة مماثلة لمتغيرات الدراسة الحالية مع طلبة جامعة ام القرى. • اجراء دراسة تتمثل في متغير الاحباط مع متفيرات دراسية مختلفة. • اجراء دراسات مقارنة بين طلبة الجامعة في دافعية الانجاز مع متفيرات دراسية مختلفة. • عمل برنامج تدريبي للحد من الاحباط لاى بعض طلاب الجامعة. • عمل برامج تدرببية للارتقاء بمستوى دافعية الانجاز لاى طلبة الجامعة. 


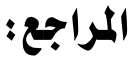

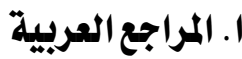

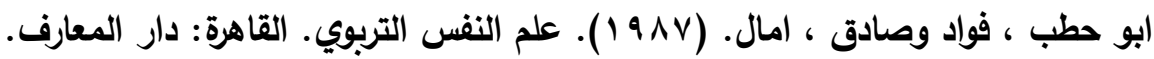

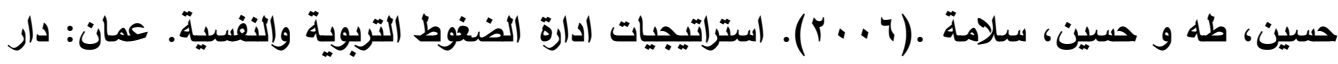
الفكر.

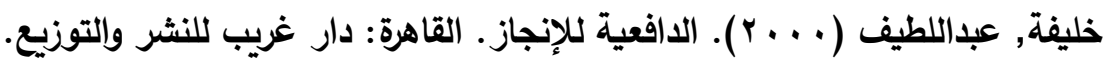

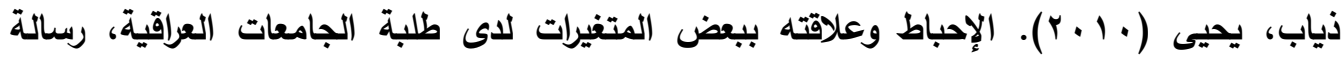

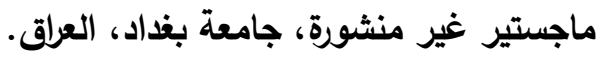

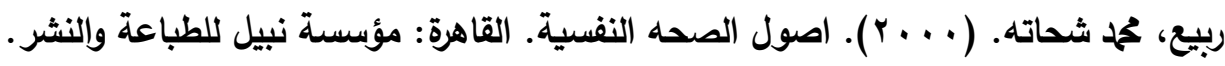

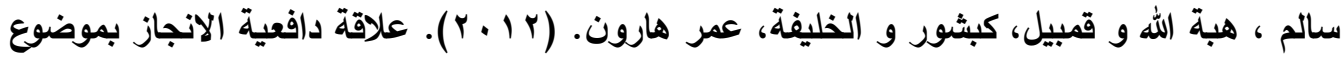
الضبط ومستوى الطموح والتحصيل الدراسي لاى طلاب مؤسسات التعليم العالي بالسودان.

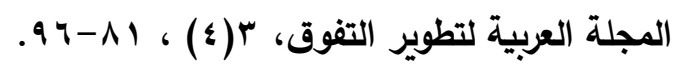

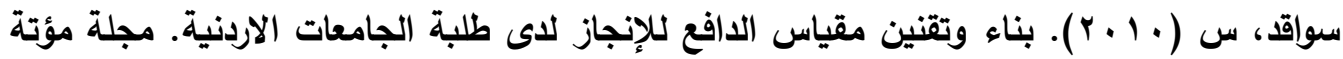

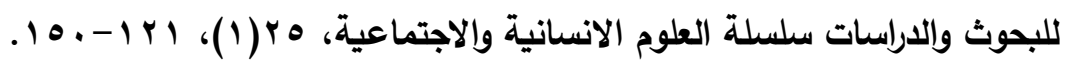

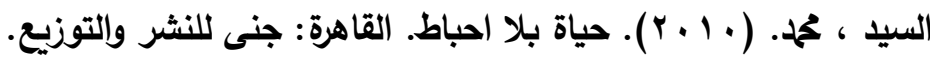

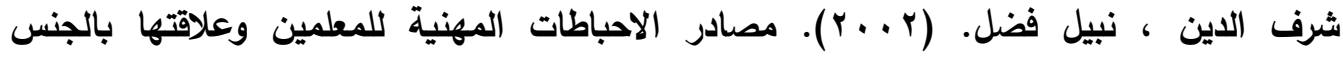

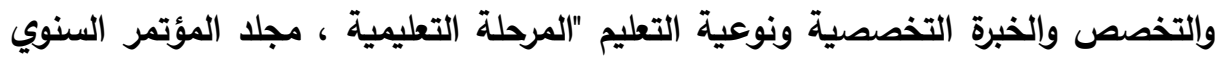

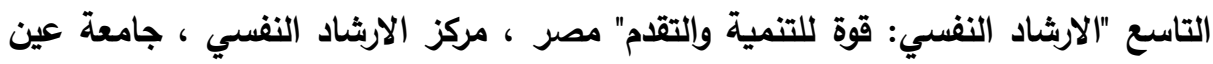
شمس.

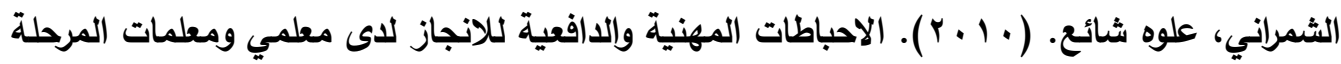

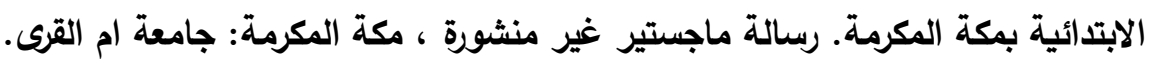

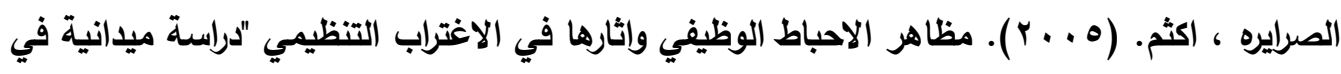
المنظمات الصحية العامة في المملكة الاردنية الهاشمية" مجلة دراسات العادية العلوم الادارية،

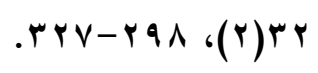

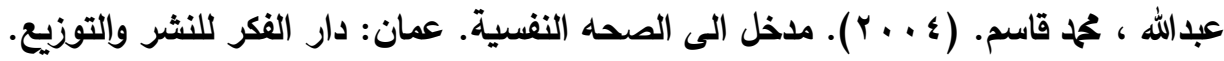

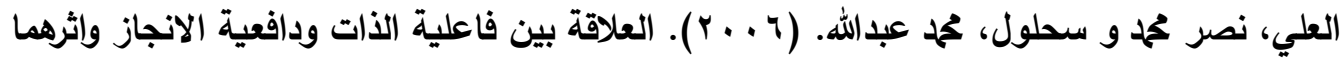

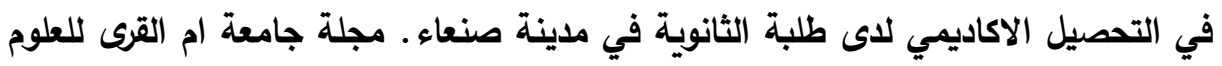

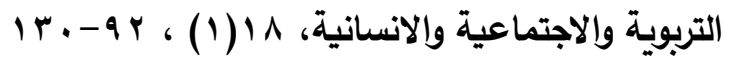




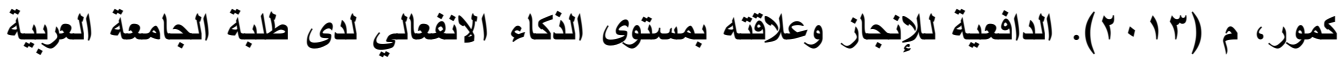
المفتوحة (فرع الاردن)، مجلة جامعة القدس المفتوحة للأبحاث والدارسات التربوية

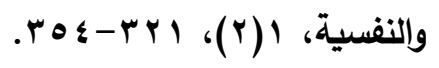

محمل ، محم و مرسي ، كمال. (997 (19). الصحة النفسية في ضوء علم النفس والاسلام. الكويت: دار

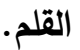

مواري، ادوارد. (911 1). الدافعية والانفعالات. ترجمة احمد سلامه عبدالعزيز و محمد عثمان نجاتي ،

$$
\text { مكتبة اصول علم النفس الحديثة. }
$$

نوفل، م (11 ـ (1). الفروق في دافعية التعلم المستندة الى تقرير الذات لاى عينة من طلبة كليات

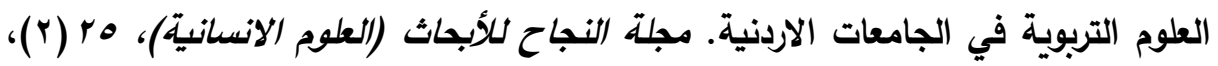

$$
r \cdot v V-r \cdot \Lambda
$$

اليوسف, رامي. ( • • + ). علم النفس التربوي بين النظرية والتطبيقات الصفية. حائل، دار الاندلس

$$
\text { للطباعة والنشر . }
$$

اليوسف، رامي (1^ • Y). الدافعية للإنجاز لاى طلبة الدراسات العليا في الجامعة الاردنية في ضوء

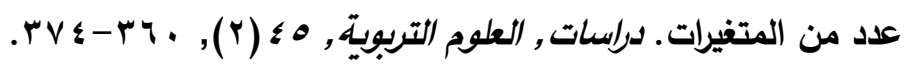

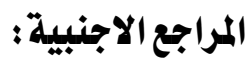

Abuameerh, Oraib \& ALSaudi, Musa ( $r+1 r)$. The R \& ALSaudi, Musa ( $r+1 r)$. The Relationship between Achievement Motivation and Academic Achievement for Secondary School Students at Salt in Jordan. Educational Sciences $r q(1), r i r-r r$.

Folkman, S. $(r \cdots r)$. Levels of intrinsic motivation and its correlates with level of personal controlling process, Journal of applied psychology, $1, r r r-r \leqslant r$.

Gulzar, Shazia., Yahya, Farzan., Nauman, Muhammad., Mir, Zarak., \& Mujahid, Syed. $(r \cdot \mid r)$. Frustration among University students in Pakistan. International Research Journal of Social Sciences, $\left.(\xi), V_{-}\right){ }^{\circ}$.

Lepper, Mark $(r \ldots \bullet)$. Intrinsic and Extrinsic Motivational Orientations in the classroom: Age Differences and Academic Correlates. Journal of Educational Psychology, $9 \vee(\curlyvee), 1 \wedge \varepsilon_{-} \mid \uparrow$.

Mavis, B. $(\uparrow \cdots 1)$. Self-Efficacy and OSCE Performance Among Second Year Medical Students, Journal of Advances in Health Science Education, vol. `, Netherlands, Kluwer Academic Publishers.

Petri, H; and Govern, J ( $\uparrow \ldots$ — $)$ ). Motivation: Theory, Research and Applications. Thomson - Wadsworth, Australia.

Pieper, S. L. $(r \ldots r)$. Refining and Extending the $r^{r} r^{r}$ Achievement Goal Framework: Anther Look at work- Avoidance. 